NASA Technical Memorandum 4426

\title{
Subsonic Flight Test Evaluation \\ of a Propulsion System \\ Parameter Estimation Process \\ for the F100 Engine
}

John S. Orme and Glenn B. Gilyard

Dryden Flight Research Facility

Edwards, California

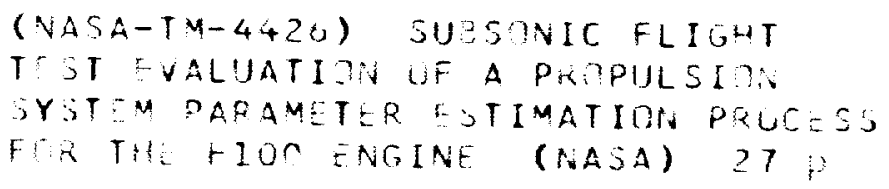

Office of Management 


\title{
SUBSONIC FLIGHT TEST EVALUATION OF A PROPULSION SYSTEM PARAMETER ESTIMATION PROCESS FOR THE F100 ENGINE
}

\author{
John S. Orme* and Glenn B. Gilyard** \\ NASA Dryden Flight Research Facility \\ Edwards, California
}

\begin{abstract}
Integrated engine-airframe optimal control technology may significantly improve aircraft performance. This technology requires a reliable and accurate parameter estimator to predict unmeasured variables. To develop this technology base, NASA Dryden Flight Research Facility (Edwards, CA), McDonnell Aircraft Company (St. Louis, MO), and Pratt \& Whitney (West Palm Beach, FL) have developed and flight-tested an adaptive performance seeking control system which optimizes the quasi-steady-state performance of the F-15 propulsion system. This paper presents flight and ground test evaluations of the propulsion system parameter estimation process used by the performance seeking control system. The estimator consists of a compact propulsion system model and an extended Kalman filter. The extended Kalman filter estimates five engine component deviation parameters from measured inputs. The compact model uses measurements and Kalman-filter estimates as inputs to predict unmeasured propulsion parameters such as net propulsive force and fan stall margin. The ability to track trends and estimate absolute values of propulsion system parameters was demonstrated. For example, thrust stand results show a good correlation, especially in trends, between the performance seeking control estimated and measured thrust.
\end{abstract}

\section{Nomenclature}

$A, B, C, \quad$ state variable model matrices $D, L, M$

\section{$A A H T$ high-pressure turbine area component deviation parameter, in ${ }^{2}$}

*Aerospace Engineer.

** Aerospace Engineer. Member AIAA.

Copyright (C) 1992 by the American Institute of Aeronautics and Astronautics, Inc. No copyright is asserted in the United States under Title 17, U.S. Code. The U.S. Government has a royalty-free license to exercise all rights under the copyright claimed herein for Governmental purposes. All other rights are reserved by the copyright owner.

\author{
$A J \quad$ nozzle throat area, in ${ }^{2}$ \\ $B L D \quad$ bleed air, $\mathrm{lb} / \mathrm{sec}$ \\ $C I V V$ compressor inlet variable guide vane \\ angle, deg \\ CPSM compact propulsion system model \\ DEEC digital electronic engine control \\ $D E H P T$ high-pressure turbine component \\ deviation parameter, percent \\ DELPT low-pressure turbine component \\ deviation parameter, percent \\ $D N O Z \quad$ nozzle drag, lbf \\ $D R A M \quad$ ram drag, lbf \\ $D W F N A$ fan airflow component deviation \\ parameter, lb/sec \\ $D W H P C$ high-pressure compressor airflow compo- \\ nent deviation parameter, $\mathrm{lb} / \mathrm{sec}$ \\ EPR engine pressure ratio, $P T 6 / P T 2$ \\ $F$ \\ steady-state variable model sensitivity \\ matrix \\ $F G \quad$ gross thrust, lbf \\ FN net thrust, lbf \\ FNP net propulsive force, $\mathrm{lbf}$ \\ FTIT fan turbine inlet temperature, ${ }^{\circ} \mathrm{R}$ \\ $h \quad$ pressure altitude, $\mathrm{ft}$ \\ $H P X \quad$ power extraction, hp \\ $K \quad$ steady-state Kalman gain matrix \\ KF Kalman filter \\ $M \quad$ Mach number \\ MIL military \\ $N 1 \quad$ fan rotor speed, rpm \\ N1C2 fan rotor speed, corrected to station 2, rpm \\ N2 compressor rotor speed, rpm
}




\begin{tabular}{|c|c|}
\hline OPR & engine operating pressure ratio, $P T 4 / P T 2$ \\
\hline$P_{\mathrm{amb}}$ & ambient pressure, $1 \mathrm{~b} / \mathrm{in}^{2}$ \\
\hline$P B$ & burner pressure, $\mathrm{lb} / \mathrm{in}^{2}$ \\
\hline PLA & power lever angle, deg \\
\hline$P S 2$ & static pressure at engine face, $\mathrm{lb} / \mathrm{in}^{2}$ \\
\hline PSC & performance seeking control \\
\hline$P T$ & $\begin{array}{l}\text { total pressure, } \mathrm{lb} / \mathrm{in}^{2} \text { (used with suffixes; } \\
\text { list follows) }\end{array}$ \\
\hline$R C V V$ & $\begin{array}{l}\text { rear compressor variable guide vane angle, } \\
\quad \text { deg }\end{array}$ \\
\hline RI & Reynolds index, $\delta / \theta^{1.24}$ \\
\hline$S M F$ & fan stall margin, percent \\
\hline$S M H C$ & $\begin{array}{l}\text { high-pressure compressor stall margin, } \\
\text { percent }\end{array}$ \\
\hline SSVM & steady-state variable model \\
\hline SVM & state variable model \\
\hline$T M T$ & composite metal temperature, ${ }^{\circ} \mathrm{R}$ \\
\hline$T S F C$ & thrust specific fuel consumption, $\sec ^{-1}$ \\
\hline$T T$ & $\begin{array}{l}\text { total temperature, }{ }^{\circ} \mathrm{R} \text { (used with suffixes; } \\
\text { list follows) }\end{array}$ \\
\hline$u$ & $\begin{array}{l}\text { vector of control variables in the state } \\
\text { variable model }\end{array}$ \\
\hline$W A C C$ & $\begin{array}{l}\text { digital electronic engine control calculated } \\
\text { airflow, } \mathrm{lb} / \mathrm{sec}\end{array}$ \\
\hline$W C F A N$ & fan airflow, lb/sec \\
\hline$W C H P C$ & high-pressure compressor airflow, lb/sec \\
\hline$W F$ & gas generator fuel flow, $\mathrm{lb} / \mathrm{hr}$ \\
\hline$x$ & $\begin{array}{l}\text { vector of state variables in the state } \\
\text { variable model }\end{array}$ \\
\hline$y$ & $\begin{array}{l}\text { vector of output variables in the } \\
\text { steady-state variable model }\end{array}$ \\
\hline$\alpha$ & angle of attack, deg \\
\hline$\beta$ & angle of sideslip, deg \\
\hline$\delta$ & $\begin{array}{l}\text { reference pressure ratio, ambient pressure } \\
\text { to sea-level pressure }\end{array}$ \\
\hline$\zeta$ & $\begin{array}{l}\text { vector of component deviation parameters } \\
\text { in the compact propulsion system model }\end{array}$ \\
\hline$\theta$ & $\begin{array}{l}\text { reference temperature ratio, ambient } \\
\text { temperature to sea-level temperature }\end{array}$ \\
\hline
\end{tabular}

\section{Subscripts}

$\begin{array}{ll}b & \text { predicted trim values } \\ c & \text { corrected } \\ m & \text { measured }\end{array}$

\section{Superscripts}

$$
\begin{array}{ll}
T & \text { transpose } \\
& \text { estimated value of variable } \\
& \text { augmented Kalman filter variables }
\end{array}
$$

Prefix

$\Delta \quad$ perturbation

\section{Suffixes, PW1128 engine station numbers,} Fig. 2

$\begin{array}{ll}2 & \text { fan inlet } \\ 2.5 & \text { compressor inlet } \\ 3 & \text { compressor discharge } \\ 4 & \text { high-pressure turbine inlet } \\ 4.5 & \text { low-pressure turbine inlet } \\ 6 & \text { afterburner discharge inlet } \\ 7 & \text { nozzle throat discharge }\end{array}$

\section{Introduction}

Digital engine control and optimal control algorithms enable significant performance improvements of the integrated aircraft-propulsion system. Developing and applying this technology will contribute to both commercial and military applications by maximizing thrust and fuel efficiency and extending engine life. Most benefits are directly attributable to advances in real-time parameter estimation techniques. Such techniques enable the control system to recover latent performance from the propulsion system which, until now, has been unrealized.

To develop this optimal performance technology, NASA Dryden, McDonnell Aircraft Company, and Pratt \& Whitney have developed and flight-tested an adaptive performance seeking control (PSC) system. ${ }^{1}$ The objective was to optimize the quasi-steady-state performance of the F-15 propulsion system. The adaptive features of the PSC system are provided by the propulsion system parameter estimation routine, which automatically adjusts the onboard model to more closely match the engine hardware.

The PSC system was developed with the following optimization modes: minimum fuel at constant thrust, maximum thrust, and minimum fan turbine inlet temperature $(F T I T)$ at constant thrust. Subsonic flight testing of the PSC algorithm was conducted at NASA Dryden covering all three modes at part- and military- (MIL) power conditions. Flight results indicate that substantial benefits were obtained 
from the PSC algorithm, up to 15-percent increases in thrust, up to $100^{\circ} \mathrm{R}$ reductions in turbine temperature, and between 1- and 2-percent savings in specific fuel consumption. ${ }^{2}$ These results rely upon an accurate engine parameter estimation.

A preliminary PSC evaluation of the propulsion system parameter estimation routine was conducted with limited flight data and determined to produce "reasonable estimates." 3 In this earlier investigation only postflight models were analyzed; the effects of measurement biases, flight condition, and engine degradation were not evaluated. In a recently completed subsonic flight program, test points were specifically designed to measure the effectiveness of a propulsion system parameter estimator. This paper presents subsonic flight test and thrust stand evaluations of the parameter estimation process for nonafterburner power settings. Representative data are analyzed for the effects of engine degradation, flight condition, and measurement biases on the estimator.

\section{Aircraft Engine Description}

The PSC program has been implemented on the NASA F-15 research airplane (Fig. 1), which is a modified high-performance aircraft capable of speeds greater than Mach 2. Two PW1128 afterburning turbofan engines power the F-15. The aircraft has been modified with a digital electronic flight control system. Additional information on the F-15 can be found in Ref. 4.

The PW1128 engine used in this study is a lowbypass ratio, twin spool, afterburning turbofan technology demonstrator derived from the F100-PW-100 engine. The engine uses a full-authority digital electronic engine control system (DEEC) that is similar to the current production F100-PW220 engine controller. The DEEC provides closed-loop feedback control of corrected fan speed $(N 1 C 2)$ and engine pressure ratio (EPR) through the fuel flow $(W F)$ and the nozzle area $(A J)$ respectively. The compressor inlet variable guide vane (CIVV) and rear compressor variable vane $(R C V V)$ positions are scheduled on rotor speeds through open-loop control. The DEEC software has been modified to accommodate PSC trim commands; however, the normal DEEC control loops (i.e., $N 1 C 2$ and EPR) have not been modified. A more detailed description of the PW1128 engine can be found in Ref. 5 .

Two PW1128 engines were evaluated during the subsonic phase of the program. Initial PSC testing was conducted with a recently refurbished engine (located on the right side of the aircraft). All algorithm verification and early testing were done with this engine. All PSC design work was performed using models of a nominal engine, which represented the refurbished engine. Near the end of the subsonic flight test program, a very degraded engine was placed on the left side of the aircraft. The main degradation was in the highpressure rotor; both the compressor and turbine had significant degradation, estimated to be approximately 2 percent in both areas.

\section{Instrumentation}

A diagram of the PW1128 engine is shown in Fig. 2. The locations of the DEEC instrumentation, DEEC-calculated parameters, and the parameters estimated by the PSC system are indicated. Fan airflow (WCFAN) and engine face total pressure ( $P T 2)$ were independently modeled by both the DEEC and PSC control laws. The PSC algorithm requires only conventional DEEC-instrumented parameters as inputs, and estimates other necessary parameters within the algorithm. The engine instrumentation and PSC parameters were sampled at 20 samples/sec.

In addition to the basic engine parameters detailed earlier, the challenging nature of the technology being demonstrated required the recording of many internal algorithm variables. These additional variables provided for real-time and postflight analysis or debugging of the algorithm. More than 200 internal parameters were recorded at a rate of $100 \mathrm{samples} / \mathrm{sec}$. In the Kalman-filter ( $\mathrm{KF}$ ) estimator, the inputs, outputs, and residuals were recorded. At the compact propulsion system modeling stage, all estimated and measured inlet and engine parameters were recorded including instrumented temperatures, pressures, and control positions, and estimated stall margins, thrust, and drag components. In the optimization phase, the constraints, optimal solution, and optimizer health condition codes were recorded. Finally, the actual commands that were sent to the engine through the DEEC were recorded.

The airdata used in the PSC were obtained from the F-15 production side probes. The algorithm corrects the data for position error and location effects. All data were recorded on a pulse-code-modulation system.

\section{Performance Seeking Control System}

The PSC algorithm is a control law that attempts to optimize propulsion system steady-state performance. ${ }^{2}$ The algorithm in Fig. 3 includes parameter estimation, modeling, and optimization. Flight measurements are used as input to the propulsion system parameter identification process and then to the compact propulsion system model (CPSM), as described later. Once the updated engine model is obtained, a linearprogramming optimization routine is used to generate trims to control parameters. An essential assumption of the estimation and modeling processes is the steadystate nature of the problem. According to program objectives, only existing engine control measurements 
were used, even though performance could have been improved with additional measurements.

An extended $\mathrm{KF}$ is used to identify the differences between the nominal model and the actual fight article by producing five engine efficiency parameters which represent these differences. The estimated parameters account for low- and high-pressure core efficiencies ( $D E L P T$ and $D E H P T$, respectively), differences in fan and high-pressure compressor airflow (DWFNA and $D W H P C$ respectively), and a change in highpressure turbine area $(A A H T)$.

In the second stage of the estimation, flight measurements are augmented with the KF efficiencies to develop the CPSM. The CPSM uses the KF estimates to adjust the steady-state model to accurately represent the flight article.

Finally, the CPSM provides estimates of unmeasured propulsion system outputs, such as net propulsive force $(F N P)$ and fan stall margin $(S M F)$, to the follow-on optimization routine. The optimization routine is based on the linear-programming simplex algorithm. For this paper, there were three optimization modes: maximum thrust, minimum FTIT at constant thrust, and minimum fuel consumption at constant thrust. The optimization sends the optimal trims to the DEEC, which applies trims to the engine.

\section{Kalman-Filter Estimator}

The adaptive feature of the PSC algorithm is primarily provided by a $\mathrm{KF}$, which estimates engine effciency. The KF estimates five engine efficiency parameters, which account for engine-to-engine variations and engine deterioration. Engine operating efficiency has been modeled in a state-space perturbation formulation as follows:

$$
\begin{aligned}
& \Delta \dot{\hat{x}}=[A] \Delta \hat{x}+[B] \Delta u+[L] \hat{\zeta} \\
& \Delta \hat{y}=[C] \Delta \hat{x}+[D] \Delta u+[M] \hat{\zeta}
\end{aligned}
$$

where

$$
\begin{aligned}
& x=\left[\begin{array}{lll}
N 1 & N 2 & T M T
\end{array}\right]^{T} \\
& u=[W F A J C I V V R C V V H P X B L D]^{T} \\
& y=\left[\begin{array}{lllllll}
P T 6 & P T 4 & F T I T & N 1 & N 2
\end{array}\right]^{T} \\
& \zeta=[D E L P T D E H P T A A H T D W H P C D W F N A]^{T}
\end{aligned}
$$

The state, control, measurement, and efficiency vectors are $x, u, y$, and $\zeta$ respectively. Horsepower extraction $(H P X)$ and bleed airflow $(B L D)$ are modeled as part of the control vector, and aggregate turbine metal temperature (TMT) is modeled as part of the state vector. The state, control, and measurement perturbations are calculated from the engine data $(x, u$, $y$ ) and the predicted state, control, and measurement steady-state trim values $\left(x_{b}, u_{b}, y_{b}\right)$ where

$$
\begin{aligned}
& \Delta x=x-x_{b} \\
& \Delta u=u-u_{b} \\
& \Delta y=y-y_{b}
\end{aligned}
$$

In the PSC problem, the values for $\zeta$ are unknown and require estimation.

Engine deterioration occurs slowly relative to the dynamics of the engine state vector and is assumed to be steady state. Hence, $\dot{\zeta}$ can be approximated to be 0 . Reformulating the problem by augmenting the state vector with $\zeta$ yields:

$$
\left[\begin{array}{c}
\Delta \dot{\hat{x}} \\
\Delta \dot{\hat{\zeta}}
\end{array}\right]=\left[\begin{array}{cc}
A & L \\
0 & 0
\end{array}\right]\left[\begin{array}{c}
\Delta \hat{x} \\
\Delta \hat{\zeta}
\end{array}\right]+\left[\begin{array}{c}
B \\
0
\end{array}\right][\Delta u]
$$

and

$$
[\Delta \hat{y}]=[C M]\left[\begin{array}{c}
\Delta \hat{x} \\
\Delta \hat{\zeta}
\end{array}\right]+[D][\Delta u]
$$

After combining the $\Delta \hat{x}$ and $\hat{\zeta}$ vectors to form an augmented state vector, the above equations are written in a compact $\mathrm{KF}$ format yielding

$$
\begin{aligned}
\Delta \dot{\tilde{x}}^{\prime} & =\left[A^{\prime}\right] \Delta \hat{x}^{\prime}+\left[B^{\prime}\right] \Delta u+[K](\Delta y-\Delta \hat{y}) \\
\Delta \hat{y} & =\left[C^{\prime}\right] \Delta \hat{x}^{\prime}+[D] \Delta u
\end{aligned}
$$

where the KF gain matrix, $K$, is a function of the solution to the steady-state matrix Ricatti equation. More details concerning the KF design may be found in Luppold et al. ${ }^{6}$

The block diagram in Fig. 4 shows how the KF estimator employs the dynamic state variable model (SVM). The SVM is a piecewise linear model encompassing the entire range of engine operation at Mach 0.9 at an altitude of $30,000 \mathrm{ft}$ at standard day conditions. It consists of a state-space perturbation model and an associated table of steady-state trim values for all engine variables in the model. The perturbations of $\Delta x, \Delta y$, and $\Delta u$ represent the differences between flight-measured and model steady-state values (also referred to as basepoints, hence the subscript $b$ ). The predicted steady-state trim values are stored as a bivariate function of $P T 4$ and $P T 6$ and are for a nominal, undeteriorated engine. There are 49 sets of $A^{\prime}, B^{\prime}$, $C^{\prime}, D$, and $K$ matrices corresponding to values of $P T 4$ ranging from 23 to $260 \mathrm{lb} / \mathrm{in}^{2}$, which accommodate the engine operating range for the flight envelope corrected to the 0.9-Mach, 30,000-ft altitude reference condition.

Figure 2 shows the locations of the engine parameters. Values for the following measurements and control variables are taken directly from flight data: $N 1$, $N 2$, burner pressure $(P B), F T I T, P T 6, W F, A J$, $C I V V$, and $R C V V$. The PT4 is modeled as a function of $P B, H P X$ is modeled as a function of $N 2$, and $B L D$ is modeled as a function of Mach and altitude. 
Additional flight measurements are used by the KF for calculating other engine variables and to transform the engine data to the SVM design condition of Mach 0.9 at an altitude of $30,000 \mathrm{ft}$. Standard correction factors are used to transform the measured and calculated engine variables to different flight conditions.

The engine efficiency parameters convey operational differences between an engine model at 0.9 Mach and $30,000 \mathrm{ft}$ and the measured in-flight engine. The estimates were designed to represent the most significant influence on engine efficiency-namely, engine degradation. Included in engine degradation are component deterioration and engine-to-engine variations. However, from the mathematical formulation, the five estimates must also contain all other unknown effects, such as measurement bias and Reynolds effects. The source of measurement bias is sensor error. Reynolds effects arise from differences between the design point at $0.9 \mathrm{Mach}$ and $30,000 \mathrm{ft}$ and the flight-tested Mach and altitude. Effectively, the five estimates can be thought of as model-matching parameters or component deviation parameters. As such, they will be termed component deviation parameters throughout the remainder of this paper because they are more than simple operating efficiencies.

\section{Compact Propulsion System Model}

The second phase of the PSC parameter estimation algorithm formulates the CPSM. The CPSM is a simplified steady-state model of the engine and inlet. Estimates from the KF are included in the control input vector to the CPSM to adjust the model to more accurately reflect engine operation. The CPSM consists of a linear steady-state perturbation model of the engine, steady-state trim tables, and follow-on nonlinear calculations. Figure 5 shows the structure of the CPSM.

The linear portion of the CPSM is the steady-state variable model (SSVM). The SSVM has the form

$$
\Delta y=[F] \Delta u
$$

where

$$
\begin{aligned}
\Delta y & =y-y_{b} \\
\Delta u & =u-u_{b}
\end{aligned}
$$

The symbols $u$ and $y$ represent the control input and measurement vectors, respectively. They are defined to be

$$
\begin{aligned}
u= & {[\text { WF PT6 CIVV RCVV HPX BLD DEHPT }} \\
& D E L P T \text { DWFNA DWHPC AAHT }]^{T} \\
y= & {[N 1 C 2 \text { N2AJ PT2.5 PT4 TT2.5 TT3 TT4 FTIT }} \\
& \text { TT6 WCFAN WCHPC }]^{T}
\end{aligned}
$$

Although this model was developed for 0.9 Mach at an altitude of $30,000 \mathrm{ft}$, it was translated to the sea-level static standard day reference condition using standard correction factors. The steady-state trim values are analogous to those used with the SVM in the KF, providing the $y_{b}$ and $u_{b}$ vectors in equation (3). The SSVM trim and the matrix models $\left(y_{b}, u_{b}\right.$, and $\left.F\right)$ are scheduled as a bivariate function of PT4 and PT6 using linear interpolation between model points.

The SSVM uses engine measurements for the following control inputs: $W F, P T 6, C I V V$, and $R C V V$. The $H P X$ and $B L D$ are modeled as in the KF. The KF estimates are input to the SSVM calculation as part of the control vector. The SSVM provides estimates for the measurement vector $y$ at the sea-level static condition and then transforms those estimates back to the actual flight condition with the standard correction factors.

Following completion of the linear SSVM calculation, the nonlinear CPSM estimates are calculated. Referring again to Fig. 5, these variables include $P T 7, T T 7$, gross thrust $(F G), F N P$, ram $\operatorname{drag}(D R A M)$, nozzle drag $(D N O Z), A J N L, S M F$, and high-pressure compressor stall margin $(S M H C)$. The nonlinear calculations use a combination of analytical equations and empirically derived data tables. They are based on measured engine variables and SSVM estimates. If a variable is both measured and estimated, the flight measurement is used in the nonlinear calculations. The nonlinear outputs from the CPSM are used with the SSVM outputs by the follow-on optimization routine.

\section{Performance Seeking Controls Optimization}

The PSC optimization routine is based on linearprogramming techniques. As input the optimization uses a propulsion system matrix derived from the estimated engine variables by the CPSM. The solution to the linear-programming problem represents the local minimum within the defined constraints. By definition, the optimal solution will always be on the boundary of at least two constraints. Depending on the optimization mode, either equality or inequality constraints are placed on parameters such as FTIT, FNP, and physical boundaries.

Of the possible 18 optimization constraints, the $S M F$ estimate is often one of the two active constraints. The optimization minimum $S M F$ limit is determined by the accuracy of its calculation. The inputs to the $S M F$ calculation are EPR and fan airflow $(W A C C)$. Since EPR is considered very accurate, the $W A C C$ estimate drives the limit for minimum $S M F$. Without the adaptive features of the PSC system, the error in the $W A C C$ estimate may be as high as \pm 4 percent leading to a required $S M F$ limit of approximately 10 percent. With the adaptive features of PSC, the increased accuracy in the WACC estimate leads to a lower required minimum $S M F$ of 
4 percent. With the reduced constraint, the engine can be uptrimmed further. Therefore, the increased accuracy of the adaptive parameter estimation process leads directly to improved engine and aircraft performance benefits.

The PSC algorithm is closed-loop in a very general sense, since flight measurements are fed into the estimation and modeling. However, the optimal solution is based on models rather than flight data; as such, the algorithm may be described as a model-based command system.

\section{Evaluation Procedure}

The PSC subsonic flight testing and thrust stand testing provided an abundance of data with which to evaluate the propulsion system parameter estimation process. Maneuvers flown include aircraft accelerations and cruise flight at various altitudes and power settings on both the refurbished and degraded engines. Hence, a spectrum of flight conditions, engine operating conditions, and engine degradation levels was available from which to select data accurately representing the capability of the PSC estimation process.

The evaluation of the parameter estimation process involved analyzing the $\mathrm{KF}$ engine component deviation parameters first and then the CPSM estimated engine variables. The KF estimates have no associated measurement with which to compare. The interpretation of the absolute values of the estimates was somewhat limited because the KF model is not a fully accurate representation of the actual propulsion system. The overriding factors determining the value of the estimates and particularly their trends are power setting, engine degradation, measurement bias, and Reynolds effects. Of these known influences on the estimates, only power setting and engine degradation were modeled. Thus, some insight may be gained from observing trends in the estimates in comparison with engine degradation and power setting, or equivalently, operating pressure ratio (OPR, defined as the ratio of total burner pressure, PT4, to inlet total pressure, $P T 2$, to normalize for power setting). However, since unmodeled sources of estimation error are not separable, it is not possible to measure the sensitivity of each estimate to each known source of error.

Evaluation of the CPSM parameter estimation is most readily accomplished by direct comparison with engine measurements. Several of the SSVM-estimated parameters are also part of standard F100 instrumentation: N1C2, N2, AJ, PT4, and FTIT. The parameter $N 1 C 2$ is the measured fan rotor speed corrected to station 2 with $T T 2$. In addition, the degraded test engine had special instrumentation for PT2.5, TT2.5, and TT3. Comparisons were made between the DEEC airflow calculation and the CPSM-estimated airflow.

\section{Engine Testing}

Each of the three PSC optimization modes was tested on the refurbished and degraded engines. The minimum fuel mode was tested in steady-state cruise maneuvers, the minimum FTIT in steady-state cruise and acceleration maneuvers, and the maximum thrust mode in steady-state cruise and acceleration maneuvers. Steady-state cruise test points usually consisted of 2 min with the PSC disengaged (PSC trims calculated but not sent to the engine) followed immediately by 2 min with the PSC engaged (PSC trims calculated and sent to the engine). The 2-min time interval was determined to be an adequate period for the PSC algorithm to reach steady state. Typically, the KF estimates required the most time to reach steady state, indicating a relatively large time constant in the filter. Before commencing the test, the power setting was adjusted to the required position and was left there for the duration of the test maneuver. Acceleration test points required sustained turns for engine and algorithm stabilization after moving the throttle to the required test position. Once the engine-algorithm (i.e., the FTIT and PSC parameter estimates) stabilized, the pilot leveled the wings and began the acceleration test. The baseline configuration tests were conducted at three altitude and Mach number conditions: $15,000 \mathrm{ft}$ and 0.9 Mach, 30,000 ft and 0.9 Mach, and 45,000 ft and 0.88 Mach.

Besides the testing completed in the nominal PSC configuration, some parametric testing was also performed to determine overall algorithm robustness. During the course of the subsonic flight testing, biases on engine measurements were adjusted several times to more accurately reflect the engine hardware and instrumentation sensors. The effect of measurement biases on the estimation is of interest since it will demonstrate some of the sensitivity of the PSC algorithm to measurement errors.

\section{Degraded Engine Testing}

Tests were performed on the degraded engine to demonstrate the ability of the PSC system to adapt to various levels of engine deterioration. Specifically, the engine deterioration refers primarily to the highpressure turbine. These blades and vanes were partially eroded from extended use (if the blades had been in a production engine they would have been replaced). To a lesser extent, the high-pressure compressor was also deteriorated, mainly because of worn tip seals. The poor condition of both components adversely affected engine performance. For example, the deterioration was manifested in FTIT; the degraded engine operated 
at hotter temperatures than the refurbished engine at the same flight condition and power setting.

The state of the degraded engine is reflected in the $\mathrm{KF}$ engine component deviation parameters, CPSM engine estimates, and the optimal engine operating point. Assuming identical bias configuration and flight conditions, a comparison of the KF estimates between the refurbished and degraded engines will reflect relative differences in engine operating efficiency. Because of the deteriorated components, the state of the degraded engine differed from the nominal engine and resulted in different estimates and optimization results. Maneuvers were conducted in the same manner as described for the refurbished engine testing.

\section{Thrust Stand Testing}

A thrust stand test was performed during the course of the subsonic flight testing to demonstrate and calibrate real-time thrust calculations. ${ }^{7}$ Degraded and refurbished engines were tested on the aircraft with the PSC system engaged and disengaged. Effectively, the test setup consisted of the aircraft being tied down with a cable which was attached to strain gages to measure force supplied by the engines. The strain gages measured the gross thrust as well as any wind-induced forces, or equivalently, net thrust. Although some thrust stand procedural or hardware error may have contributed to inaccuracy in the absolute thrust readings, the trends in thrust should be accurate. Thus, the thrust stand provides a unique opportunity to evaluate the onboard thrust estimate.

\section{Results and Discussion}

Results are presented to illustrate the ability of the parameter estimation process to provide acceptable estimates of propulsion system outputs. Algorithm evaluation of the overall estimation is approached at three levels: First, KF flight data will be qualitatively analyzed for trends and comparisons made with predictions; second, the CPSM estimates will be compared with available measurements; third, the effect of parametric variations on the estimation process will be shown.

\section{Kalman Filter Component Deviation Parameters}

The trends and levels of the five KF estimates are evaluated at different flight conditions, power settings, and engine health. The values of DELPT, DEHPT, $A A H T, D W H P C$, and $D W F N A$ are each plotted as a function of OPR. In general, the OPR points reflect tests done at nominal power level angle (PLA) values of $40^{\circ}, 50^{\circ}, 60^{\circ}, 70^{\circ}$, and MIL. Engine component deviation parameters from refurbished engine testing at the KF design point of $0.9 \mathrm{Mach}$ and $30,000 \mathrm{ft}$ are presented to establish baseline magnitudes for these estimates. Then, the variation of the engine component deviation parameters with respect to flight condition is evaluated. Next, the sensitivity of the KF estimation to measurement biases is examined. Finally, the effect of engine degradation on the KF estimates is presented.

Besides the modeled engine degradation effects, the $\mathrm{KF}$ engine component deviation parameters include many effects which are not explicitly modeled. Among the more influential factors are flight condition (Reynolds effects) and measurement bias. Boundarylayer and flow separation variations with flight condition are examples of Reynolds effects. Measurement biases are known to exist for the engine instrumentation of $A J, F T I T$, and $W F$. Measurement bias estimates were obtained by the engine manufacturer based on detailed analysis of ground runs and flight results. Accordingly, the data presented in this paper were obtained with the resulting set of biases: $+70^{\circ}$ for FTIT, $+2.0 \mathrm{in}^{2}$ for $A J$, and $+180 \mathrm{lb} / \mathrm{hr}$ for $W F$ for the re furbished engine, and $+70^{\circ}$ for FTIT for the degraded engine. Thus, any remaining bias is probably small. Later, results are presented with a preliminary bias configuration $\left(+40^{\circ}\right.$ for $F T I T,-2.9 \mathrm{in}^{2}$ for $\left.A J\right)$ used with the refurbished engine.

As stated earlier, the PSC command system is model based, and as such, will produce similar results whether engaged or disengaged; differences are caused by relatively small changes in the engine operating point. Since the objective of this paper is to evaluate the estimator, this evaluation will be comparable whether or not PSC is commanding optimal trims to the engine. The results obtained with the PSC system disengaged were more complete and of better quality; therefore, these results are used for most results presented throughout the paper.

\section{Baseline Results}

Steady-state testing with the refurbished engine at 0.9 Mach and $30,000 \mathrm{ft}$ minimizes the influences of flight condition and engine degradation on the $\mathrm{KF}$ estimates. Still, there are modeling errors. The refurbished engine is not exactly the same as the engine model, and there are sensor biases. If the model contained no error, the KF estimates would be zero for the nominal engine at the design flight condition.

Figure 6 presents the KF engine component deviation parameters for refurbished engine testing done at 0.9 Mach and $30,000 \mathrm{ft}$. The OPR ranges from 12 at $40^{\circ}$ PLA to 29 at MIL PLA. Overall, the estimates are well behaved and follow smooth trends indicating reasonable KF estimates. However, not surprisingly, the onboard-determined engine component deviation 
parameters are not zero. The following paragraphs discuss the component deviation parameters of Fig. 6 :

Low-Pressure Turbine Component Deviation Parameter. 'The estimated DELP'' (combination of fan and low-pressure turbine) is low relative to the engine model, ranging from -15 percent at $\mathrm{OPR}=12$ to -1 percent at $\mathrm{OPR}=29$. The -15 percent at $\mathrm{OPR}=$ 12 , where PLA is $40^{\circ}$, may be too low since at other OPRs, the DELPT lies within \pm 5 percent.

High-Pressure Turbine Component Deviation Parameter. The estimated DEHPT (combination of compressor and high-pressure turbine) of the refurbished engine decreases very little relative to the engine model with increasing engine operating ratio, from 0.2 percent at $\mathrm{OPR}=12$ to -3 percent at $\mathrm{OPR}=29$.

High-Pressure Turbine Area Component Deviation Parameter. The estimated $A A H T$ (or gas flowpath area) of the refurbished engine decreases relative to the engine model with increasing engine operating ratio, from $1.3 \mathrm{in}^{2}$ at $\mathrm{OPR}=12$ to $-1.3 \mathrm{in}^{2}$ at $\mathrm{OPR}=29$.

High-Pressure Compressor Airflow Component Deviation Parameter. The estimated $D W H P C$ displays trends similar to those observed with the high-pressure spool component deviation $D E H P T$. The DWHPC of the refurbished engine decreases very little relative to the engine model with increasing engine operating ratio, from $1 \mathrm{lb} / \mathrm{sec}$ at $\mathrm{OPR}=12$ to $-1 \mathrm{lb} / \mathrm{sec}$ at $\mathrm{OPR}=29$.

Fan Airflow Component Deviation Parameter. The estimated $D W F N A$ exhibits a minimum of $-4 \mathrm{lb} / \mathrm{sec}$ at $\mathrm{OPR}=18$. The $D W F N A$ of the refurbished engine increases overall with respect to the engine model from $-3 \mathrm{lb} / \mathrm{sec}$ at $40^{\circ} \mathrm{P} / \mathrm{A}$ to $-0.7 \mathrm{lb} / \mathrm{sec}$ at MIL PIA. The $70^{\circ}$ PLA point where OPR $=26$ appears to be another irregularity that is inconsistent with the general trend.

An indication of the significance of the KF estimates is obtained by comparing the flight test and theoretically predicted values. From the data, the estimates were seen to have nonzero values indicating that the flight article is not like the model. Whether these differences are important will be determined by examining the effects of known biases and engine degradation at $0.9 \mathrm{Mach}$ and $30,000 \mathrm{ft}$. To cvaluate the impact of the magnitude of the $\mathrm{KF}$ engine component deviation parameters on the total PSC system, a comparison is presented later for the CPSM estimation process with $\mathrm{KF}$ estimates as input and with zeroes as input at 0.9 Mach and $30,000 \mathrm{ft}$.

\section{Flight Condition Effects}

The KF estimation was evaluated with steadystate flight test data at three different altitude and Mach-number combinations for the degraded engine: 0.9 Mach, 15,000 ft; 0.9 Mach, 30,000 ft; and 0.88 Mach, $45,000 \mathrm{ft}$. Corresponding to each flight condition is a Reynolds index (RI). The RI is calculated as a function of inlet stagnation temperature and pressure $\left(0=T T 2 / 518.9\right.$ and $\left.\delta=P T 2 / 14.696 ; \mathrm{RI}=\delta / \theta^{1.24}\right)$, and is an indication of the thermodynamic properties of the free-stream air. The variation of each engine component deviation parameter with flight condition will indicate the overall effect of RI. Engine degradation and measurement bias are assumed not to vary with flight condition, but Reynolds effects certainly do. By cxamining each estimate at the three tested conditions, the Reynolds effects will be indicated. Each of the engine component deviation parameters is plotted as a function of OPR at the three flight conditions in Fig. 7.

The parameter DELPT of the degraded engine shows a strong dependency on flight condition. For power settings ranging between an OPR of 10 and 30 , the deviation is highest at $0.9 \mathrm{Mach}$ and $15,000 \mathrm{ft}$ and lowest at $0.88 \mathrm{Mach}$ and $45,000 \mathrm{ft}$ relative to the nominal engine. Differences from the 0.9-Mach, 30,000$\mathrm{ft}$ design point are clearly seen in Fig. 7 ; at 15,000 $\mathrm{ft}, D E L P T$ ranges up to 7 -percent higher, and at $45,000 \mathrm{ft}$ it varies as much as 7-percent lower.

The estimated DWFNA and to a lesser extent DEHPT, like DELITT, also display tendencies with flight condition. Such tendencies are most noticeable at $15,000 \mathrm{ft}$ and least noticeable at $45,000 \mathrm{ft}$. The estimated $A A H T$ and $D W H P C$ exhibit less pronounced trends with flight condition than the other three $\mathrm{KF}$ estimates. In general, $A A H T$ and $D W H P C$ show small increases with increasing altitude. Other than one test point at OPR $=24$ at $45,000 \mathrm{ft}$, the estimated $D W H P C$ is negative at all test conditions, indicating less high-pressure compressor airflow than is modeled by the nominal engine. The probable cause of the subnominal airflow is engine degradation relative to the model.

To determine the individual contributions of Reynolds effects to the estimation would require knowing the biases. The fact that these results were obtained with a degraded engine should not affect conclusions relative to Reynolds effects. Of the three flight conditions tested, all five estimates displayed the least variation with OPR at the 0.9-Mach, 30,000-ft design condition. The DELPT, DEHPT, and DWFNA 
were seen to decrease, and the $A A H T$ and $D W I I P C$ increase with increasing altitude or decreasing RI.

\section{Measurement Bias Results}

The refurbished engine was tested with two sets of measurement biases for $A J, W F$, and FTIT. To correct for what was believed to be measurement bias, corrections were added to the appropriate measurements before being used in the PSC algorithm. What will be referred to as the final bias set 1 consisted of $+70^{\circ}$ FTIT, $+2.0 \mathrm{in}^{2} A J$, and $+180 \mathrm{lb} / \mathrm{hr} W F$ measurement biases, and the preliminary bias set 2 consisted of $+40^{\circ}$ FIIT and $-2.9 \mathrm{in}^{2} A J$. Data were collected at 0.9 Mach and $30,000 \mathrm{ft}$ for cruise points at four partial- and MII-power settings for the final bias set 1 and two partial- and MII,-power settings for the preliminary bias set 2 . The resulting $\mathrm{KF}$ estimates are shown in Fig. 8 as a function of OPR. The data for bias set 1 represent the biases believed to be most accurate. Bias set 2 are values used early in the program.

The estimated DELPT of the refurbished engine tends toward zero with increasing OPR for both bias sets. The two bias sets result in DELPT differing by up to 23 percent at the lowest OPR $\left(\sim 40^{\circ} \mathrm{PL} \Lambda\right)$ but by only 3 percent at the highest OPR $(\sim$ MIL PL $\Lambda)$. For all tested OPRs $(12 \sim 30)$, the final bias set 1 resulted in lower values for DELPT. Similarly, the differences in the estimated DWFNA between the bias sets are greatest at the lowest OPRs $(12 \mathrm{lb} / \mathrm{sec})$ and least at the highest OPRs (1 lb/sec).

The estimated DEHPT for the final bias set 1 resulted in higher values for DEHPT, over the range of OPRs. The differences in the estimated $A A H T$ between the bias sets decrease with increasing OPR. Overall, the final bias set 1 resulted in greater values for $A A H T$. For all tested OPlis, bias set 1 resulted in more positive values for $D W H P C$.

In general, it appears that the effect of biases is more exaggerated at lower OPRs or power settings and that the biases have less effect at the higher power settings. At MIL PLA, some engine parameters are rumning on operating limits and physical boundaries, and as such there is little or no effect of measurement bias. However, as PLA is reduced, fewer engine parameters are operating on limits, and the effects of measurement bias will be more pronounced. KF estimation sensitivity to individual measurement bias on FTIT, $A J$, or $W F$ (as opposed to a combined bias set) is unclear since no parametric bias data are currently available. The results presented above represent the cumulative effects of a difference in biases of $30^{\circ} \mathrm{FTIT}, 4.9 \mathrm{in}^{2} \mathrm{AJ}$, and $180 \mathrm{lb} / \mathrm{hr} W F$. Additional bias evaluations are made later for the CPSM estimation.

\section{Engine Degradation Results}

Steady-state data gathered on the degraded and refurbished engines (with bias set 1) at 0.9 Mach and $30,000 \mathrm{ft}$ are compared to gauge the overall effect of engine deterioration on the $\mathrm{KF}$ estimates. The data are shown in Fig. 9.

The estimated DELPT displays very little variation between the refurbished and degraded engines except at lower OPRs. Estimates of DELPT for both engines increase with increasing OPR. The estimated DEIIPT also shows small variations with engine degradation. Estimates of DEHPT for both engines decline slightly with increasing OPR.

The estimated $A A H T$ decreases with increasing OPR for both engines, although there is some indication of differences with engine degradation. The $A A H T$ estimate for the refurbished engine decreases by $3 \mathrm{in}^{2}$ over the Ol'R range, whereas the $A A H T$ estimate for the degraded engine decreases by only $0.5 \mathrm{in}^{2}$.

The estimated $D W H P C$ decreases more for the refurbished engine than for the degraded engine. For all tested OPRs, the degraded engine results show lower DW $I P C$ estimates than those for the refurbished engine, as much as $3 \mathrm{lb} / \mathrm{sec}$ lower. The DWFNA variation with OPR for the refurbished engine is much greater than that observed with the degraded engine.

For the data in Fig. 9, the condition of the degraded engine is not obvious based on the engine component deviation estimates. This may indicate insufficient fidelity in the KF model and suggests that the engine component deviation estimates are more accurately referred to as model-matching parameters. Data clearly do not correlate with known degradation of the highpressure spool. Comparisons of absolute magnitudes of any one KF estimate are inconclusive as to the effects of engine degradation, even at the design point of 0.9 Mach and 30,000 ft. Overall, the KF estimation for the refurbished engine shows more sensitivity with respect to power setting than the degraded engine. Based upon the $\mathrm{KF}$ model, it would be expected that the trends in the engine component deviation parameters with OPR would be relatively constant or at least small. These results may indicate better overall modeling for the degraded engine.

\section{Compact Propulsion System Model Estimates}

The CPSM estimates and associated measurements will be compared for the end-to-end estimation process. Flight condition and measurement bias effects on the CPSM estimates will also be reviewed. The parameters to be compared are $N 1 C 2, N 2, A J, P T 4$, FTIT, TT2.5, PT2.5, and TT3. The measurements 
for PT4, TT2.5, and TT3 are based on single-point sensors, whereas the CPSM estimation produces averaged values for these parameters. A comparison of the CPSM estimate for net thrust is made with thrust stand data.

The results of the KF estimation are an intermediate step to the objective of the PSC algorithm. Successful PSC operation requires accurate CPSM estimates for such crucial parameters as $S M F, F T I T$, and FNP. Comparison of measured to estimated FTIT will yield an assessment of model accuracy. As for the $S M F$ and $F N P$, no associated in-flight measurements were made and as such, these parameters must be estimated; this was done with established thermodynamic relationships. Inputs to the $S M F$ and $F N P$ calculations are based on measurements rather than estimates, when the measurements are available. By comparing these measurements with the associated estimates, overall model accuracy may be further surmised. However, absolute model accuracy of the $S M F$ and FNP estimates cannot be realized without additional instrumentation and knowledge about the fidelity of the thermodynamic relations.

\section{Baseline Results}

Data gathered on the degraded engine at a MILpower setting for an acceleration at the design altitude of 30,000 ft serve as baseline for comparison. The degraded engine was chosen for this analysis because it had more instrumentation than the refurbished engine. Although the results are from testing of a degraded engine, the CPSM should produce results independently of engine deterioration. The CPSM-estimated values for the five measured inputs $N 1 C 2, N 2, A J, P T 4$, FTIT, and estimated values for $P T 2.5, T T 2.5$, and TT3 are shown in Fig. 10 along with the corresponding measured values. Compared also are the CPSMestimated fan airflow $W A C C$ and the independent DEEC calculation. The following paragraphs discuss the CPSM estimates of Fig. 10:

Fan Rotor Speed, Corrected to Station 2. The decreasing trend of $N 1 C 2$ compares favorably with the measured value over the acceleration. Near $0.88 \mathrm{Mach}$, the slope of measured N1C2 decreases and the estimate does not change slope until approximately Mach 0.95 , indicating some apparent lag. The estimated absolute value of $N 1 C 2$ is as much as 1.5 -percent greater than the measurement.

Compressor Rotor Speed. The trend of the estimated $N 2$ does not agree as well as expected with its measurement, although neither vary significantly with Mach number. The difference in absolute value for $N 2$ between the estimated and measured value is less than 1 percent.
Nozzle Throat Area. The estimated $A J$ is up to 2.5-percent less than the measured value. The estimated $A J$ is actually an effective nozzle area, related to the physical $A J$ by the discharge coefficient which can be quite large. As such, it can be expected that the effective nozzle area may be up to 10 -percent less than the physical area. Since the estimate is less than the measurement, the trend is in the right direction.

Total Pressure at the High-Pressure Turbine Inlet. Trends of the estimated PT4 agree well with the measurement. The estimated value for $P T 4$ is always low and as much as 4 -percent less than the measured value.

Fan Turbine Inlet Temperature. The CPSM estimate of the FIIT agrees to within $20^{\circ} \mathrm{R}$ of the measurement. Overall the trends agree well, but the FTIT estimate appears to lag the measurement.

Total Pressure at the Compressor Inlet. Trends of the estimated PT2.5 agree very well with the measurement, although the value is low over the Mach range. The estimated PT2.5 is never more than 2 -percent less than the measured value.

Total Temperature at the Compressor Inlet. The estimated $T T 2.5$ does a fair job in tracking the dynamics seen in the measurement. At the lower Mach numbers, the estimated $T T 2.5$ is 2.5 -percent less than the measured value.

Compressor Discharge Total Temperature. The estimated TT3 agrees well with the trends of the measurement. A relatively constant offset error of no more than $40^{\circ}$ or 3 percent is observed between the estimated and measured values of $T T 3$.

Digital Electronic Engine Control Calculated Airflow. The estimated $W A C C$ is up to 2-percent greater than the DEEC calculated airflow. The DEEC airflow is limited to a maximum of $246 \mathrm{lb} / \mathrm{sec}$ for most of the acceleration, but the CPSM estimates airflow up to $4.5 \mathrm{lb} / \mathrm{sec}$ higher midway through the acceleration. Near the end of the acceleration, both airflow estimates are reduced and in better agreement.

The majority of the CPSM estimates lie within a moderately accurate 3-percent error band over the high subsonic Mach region at 30,000 ft. Discrepancies in the estimates might be the result of either a lack of engine modeling fidelity, including installation and instrumentation errors, or unmodeled measurement biases.

\section{Measurement Bias Results}

Data were gathered on the refurbished engine at a MIL-power setting for an acceleration at $30,000 \mathrm{ft}$ for two different bias configurations. The same bias sets used for analyzing the KF estimation are used here 
(the final bias set 1: $+70^{\circ} F T I T$, $+2.0 \mathrm{in}^{2} A J$, and $+180 \mathrm{lb} / \mathrm{hr} W F$ measurement biases; and the preliminary bias set 2 : $+40^{\circ} F T I T$ and $-2.9 \mathrm{in}^{2} \mathrm{AJ}$ measurement biases). The CPSM-estimated values for the five measured inputs $N 1 C 2, N 2, A J, P T 4, F T I T$ are shown in Fig. 11 along with the corresponding measured values for both bias configurations. The CPSMestimated airflow is also overplotted with the production DEEC-calculated airflow.

The magnitude of estimation error for the $N 1 C 2$ seems to be more accentuated with the final bias set 1 , whereas the preliminary bias set 2 displays less consistent behavior in the higher Mach region. The $N 1 C 2$ estimate for bias set 1 is as much as $185 \mathrm{rpm}$ less than the measurement. The magnitude of estimation error for the $A J$ with the preliminary bias set 2 is almost twice as great as that with the final bias set 1 . Bias set 2 results in an estimate as much as 10 in $^{2}$ less than the measured value. The magnitude of estimation error for the FIIT is slightly more with bias set 2 than bias set 1 . The difference of the CPSM-estimated total engine airflow, $W A C C$, and the DEEC-calculated $W A C C$ is greatest with bias set 2 .

Overall, the final bias set 1 produces more accurate CPSM estimates. In particular the estimates for $A J$, $F T I T$, and $W A C C$ appear to benefit from bias set 1 . The magnitude of estimation error for $N 2$ and the PT4 is about the same for either bias set.

\section{Altitude Results}

The effect of altitude on the CPSM estimation is analyzed with data gathered on the degraded engine at a MIL-power setting for accelerations at 15,000,30,000, and 45,000 ft. The CPSM-estimated values for the five measured inputs $N 1 C 2, N 2, A J, P T 4, F T T T$, and estimated values for $P T 2.5, T T 2.5, T T 3$, and $W A C C$ are shown in Figs. 12 and 13 for the accelerations at 15,000 and $45,000 \mathrm{ft}$, respectively, and from Fig. 10, shown previously, at $30,000 \mathrm{ft}$ along with the corresponding measured values.

The magnitude of estimation error for both the $N 1 C 2$ and the PT4 decreases with increasing altitude. The amount of PT4 estimation error ranges from 3 percent at $45,000 \mathrm{ft}$ to 5.5 percent at $15,000 \mathrm{ft}$. The magnitude of estimation error for the $A J$ also decreases with increasing altitude.

Very good estimates are made for the $N 2$ and the FTIT. The maximum estimation error observed was less than 1 percent for both estimates, and is minimized to nearly zero at $15,000 \mathrm{ft}^{\prime}$.
The errors for the estimated $P T 2.5, T T 2.5$, and $T T 3$ display no clear trends with altitude. The estimation error for TT3 is about 3 percent throughout the three altitudes.

The differences in the CPSM and DEEC tatal corrected engine airflow, $W A C C$, decrease with increasing altitude. At $45,000 \mathrm{ft}$, the estimated $W A C C$ is approximately 1-percent greater than the DEEC airflow and about 2-percent greater at $15,000 \mathrm{ft}$ and $30,000 \mathrm{ft}$.

Good CPSM estimates are found for the MII-power setting at all the flight-tested altitudes. Unexpectedly, the most accurate estimation occurs at altitudes other than the design condition, 30,000 ft. Estimation accuracy is defined as the largest observed difference between each estirrate and its corresponding sensor reading, at the same time noting the sensor accuracy. The table below presents, for each estimated parameter, the largest observed difference between measurement and estimate along with the sensor accuracy. The differences represent the combined effects of sensor inaccuracies and modeling uncertainty. Fortunately, the least accurate estimate, PT4, is also measured, and the measurement is used by the CPSM for other estirnation outputs. The error for $A J$ estimate includes the differences between the geometric measurement and the model-calculated effective area. The TT3 estimation error did not vary with altitude; this probably represents a discrepancy due to single-point sensor measurement not representing the average value of the engine. The PT2.5 and 'T'T2.5 estimation error probably' contains effects from the assumption in the model of standard day atmospheric conditions.

Approximate CPSM estimation accuracy.

\begin{tabular}{ccc}
\hline Estimated & $\begin{array}{c}\text { Sensor } \\
\text { parameter }\end{array}$ & $\begin{array}{c}\text { Difference, } \\
\text { accuracy, percent }\end{array}$ \\
\hline plC2 & \pm 0.5 & 1.0 \\
N2 & \pm 0.5 & -1.0 \\
AJ & \pm 1.5 & -2.0 \\
PT & \pm 3.0 & -4.0 \\
FTIT & \pm 0.5 & -0.5 \\
PT2.5 & \pm 5.0 & -2.0 \\
$T T 2.5$ & \pm 0.5 & 1.0 \\
$T T 3$ & \pm 0.5 & 3.5 \\
\hline \hline
\end{tabular}

\section{Thrust Stand Results}

Figure 14 shows the results from a thrust stand run at a MIL PLA setting for the degraded engine. The 
estimated thrust is approximately 4-percent higher than measured. The difference may be attributable to error in other PSC estimates that are used as input to the thrust calculation, or error in the modeled thrust equation. However, it is more critical for the PSC algorithm to closely match trends in thrust rather than the absolute values. As seen in the figure, the CPSM estimation performs the tracking task very well, but with an apparent lag of about $3 \mathrm{sec}$. Additional thrust stand results are presented in Ref. 7.

\section{Sensitivity of Model to Kalman-Filter Inputs}

Results were presented in Fig. 6 for the KF estimates produced in flight for the refurbished engine for an OPR of $22\left(60^{\circ} \mathrm{PLA}\right.$ setting $)$ in a cruise at Mach 0.9 and $30,000 \mathrm{ft}$. It was noted previously that the engine component deviation parameters were expected to be zero, but in real time they were not. At the $60^{\circ}$ PLA setting, the KF estimates were relatively small compared with the other power settings, but the effect of these small numbers on the follow-on CPSM estimation was unclear. To obtain a feeling for the importance of the engine component deviation parameters, the onboard CPSM model was executed postflight with zeroes used as the $\mathrm{KF}$ input to the CPSM. The resulting postflight CPSM outputs are compared with the real-time CPSM outputs and associated measurements in Fig. 15.

The estimates produced with and without the realtime $\mathrm{KF}$ values for the measured inputs $N 1 C 2, N 2$, $A J$, PT4, FTIT are overplotted with the corresponding measurements. The estimated outputs $S M F$ and $F N P$ are also overplotted for the two cases. In addition, the CPSM airflow $W A C C$ is shown for both cases plotted with the DEFC-calculated $W A C C$.

All estimates except FTIT increase when zeroes are used as input from the KF to the CPSM. The estimated nozzle area, $A J$, increases by as much as 5 percent and the estimated FTIT decreases by about 3 percent without the real-time $\mathrm{KF}$ input. The realtime estimates, in general, are in good agreement with the measurements. The estimated airflow is about 7 -percent greater with zeroes as $\mathrm{KF}$ input.

The effect of the $\mathrm{KF}$ input on the resulting $S M F$ calculation is sizable and less conservative; without the real-time inputs, the $S M F$ is reduced by about 50 percent. At least some of this decrease is caused by the increase in estimated airflow. With zeroes substituted for the real-time engine component deviation parameters, the resulting thrust calculation is about 3 -percent greater.
For the flight test point considered, all real-time KF deviation parameters were negative suggesting the refurbished engine is less efficient than the engine model. In fact, the effect on the estimated engine parameters agrees with this hypothesis. Estimated FNP for the engine model is 3 percent greater than estimated for the refurbished engine. In addition, the engine model, with zero component deviations, operates at a lower estimated FTIT than for the refurbished engine. Clearly, even seemingly small KF estimates play an important role in the PSC estimation process.

\section{Concluding Remarks}

Test results show the propulsion system parameter estimation process to be successfully operating and producing reasonable engine estimates over the entire steady-state subsonic flight envelope. Variations with flight condition, engine degradation, and measurement bias indicate the sensitivity of the performance seeking control algorithm and estimation process.

Comparisons with flight measurements indicate that the estimated inputs to the Kalman filter and compact propulsion system model are reasonable. Well-behaved estimates are produced that accurately reflect the state of the engine. The airflow estimation produces higher maximum values than those predicted by the digital clectronic engine control calculation. Thrust stand results show good correlation between the performance seeking control estimated and measured thrust.

Reynolds effects, hardware discrepancies, and engine dynamics all contribute to performance seeking control modeling error. The sensitivity of the Kalman-filter engine component deviation parameters to unmodeled altitude and measurement bias effects indicate the need for improved modeling techniques. The Kalman-filter component deviation parameters do not accurately reflect known engine degradation. The propulsion system model estimation is quite sensitive to small Kalmanfilter estimates.

\section{References}

${ }^{1}$ Nobbs, S.G., Jacobs, S.W., and Donahue, D.J., "Development of the Full-Envelope Performance Seeking Control Algorithm," $\Lambda \mathrm{I} \Lambda \Lambda-92-3748$, July 1992.

${ }^{2}$ Gilyard, Glenn B. and Orme, John S., "Subsonic Flight Test Evaluation of a Performance Seeking Control Algorithm on an F-15 Airplane," AIAA-92-3743, July 1992. 
${ }^{3}$ Maine, Trindel A., Gilyard, Glenn B., and Lambert, Heather II., "A Preliminary Evaluation of an F100 Engine Parameter Fstimation P'rocess Using Flight Data," NASA TM-4216, 1990

${ }^{4}$ Myers, Lawrence P. and Burcham, lrank W., Jr., Preliminary Flight Test Results of the F'100 EMD Engine in an F-15 Airplane, NASA TM-85902, 1984.

${ }^{5}$ Digital Electronic Engine Control (DEEC) Flight Evaluation in an F-15 Airplane. P'roceedings of a minisymposium held at the NASA Dryden Flight Research
Facility, Edwards, California, May 25 26, 1983, NASA Cl'-2298.

${ }^{6}$ Luppold, R.II., Roman, J.R., Gallops, G.W., and Kerr, L..J., "Estimating In-Flight Engine Performance Variations Using Kalman Filter Concepts," AIA A-892584, July 1989.

${ }^{7}$ Comners, Timothy R., "Thrust Stand Evaluation of Engine Performance Improvement Algorithms in an F-15 Airplane," AIAA-92-3747, July 1992.

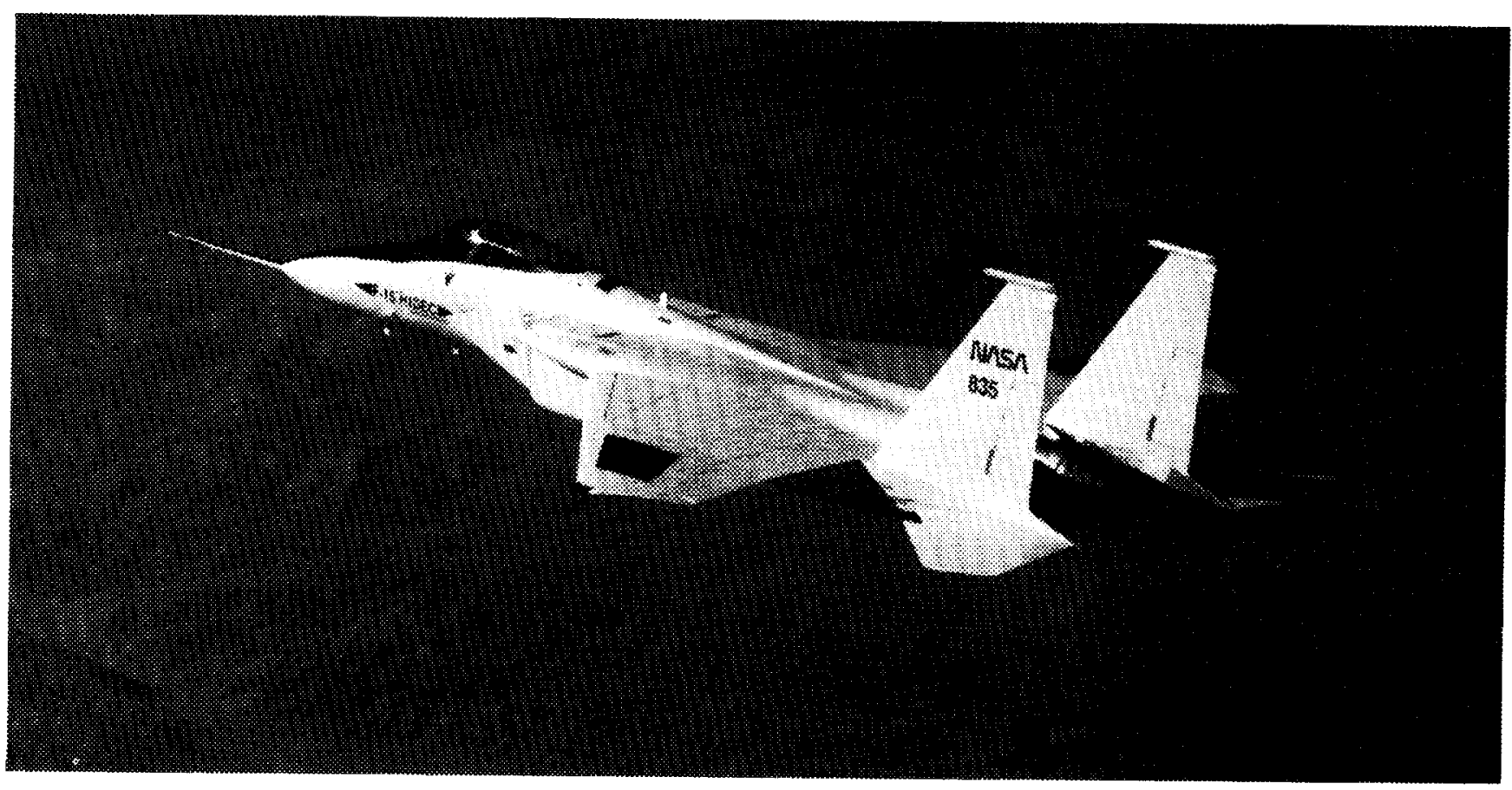

EC90 $312-11$

lig. 1. The 1-15 aircratt.

ORIGINAL PAGE

BLACK AND WHITE PHOTOGRAPH 


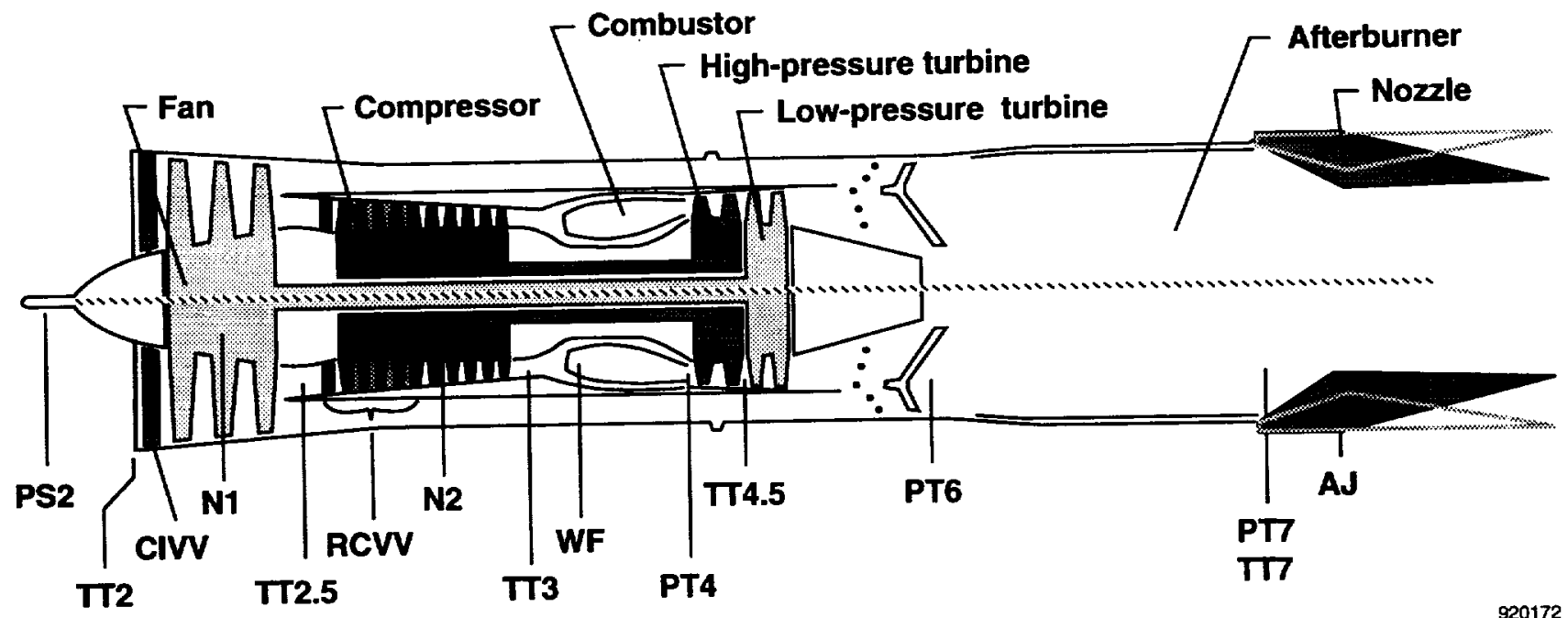

Fig. 2. F100 engine, parameter, and sensor locations.

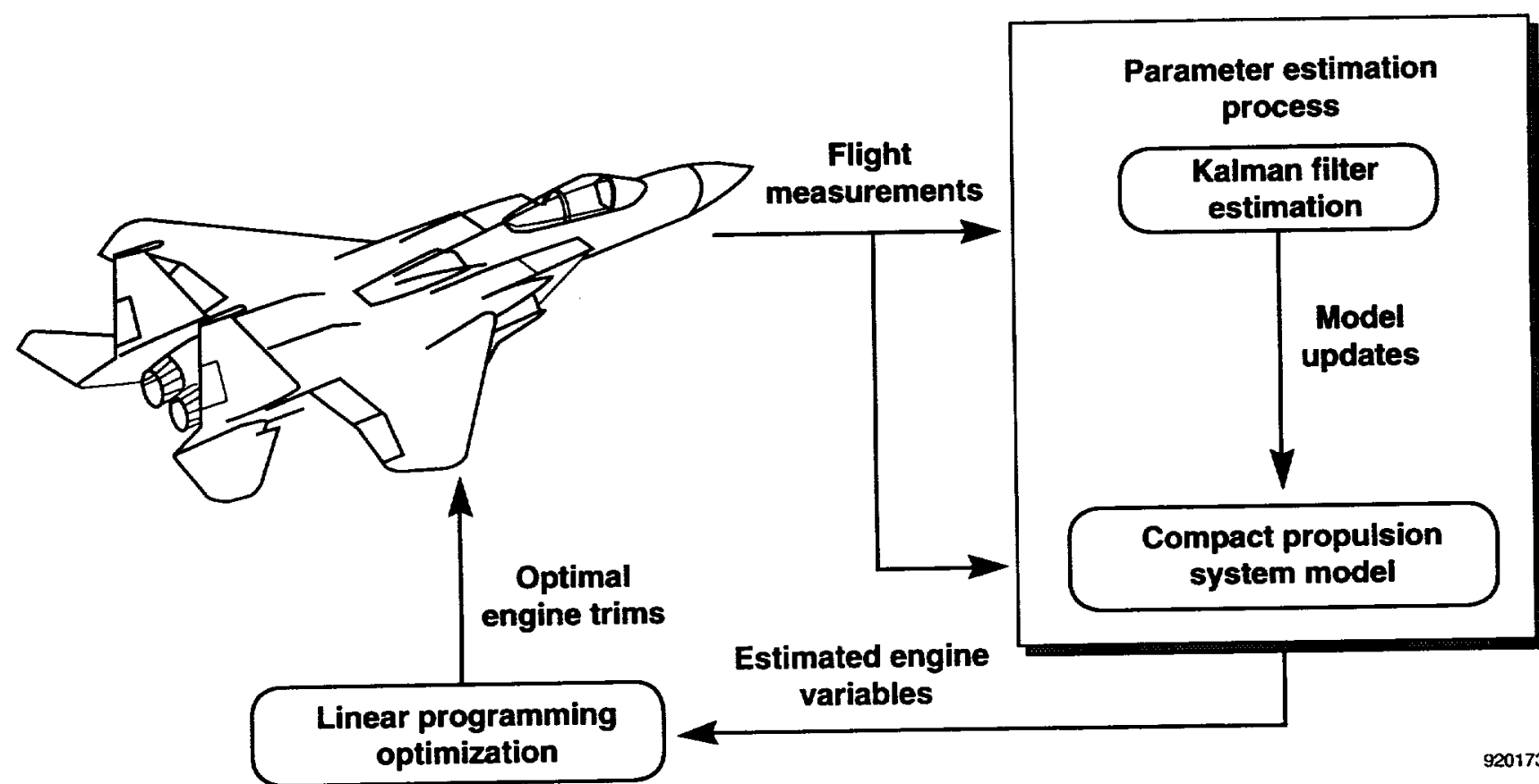

Fig. 3. Performance seeking control algorithm flowchart. 


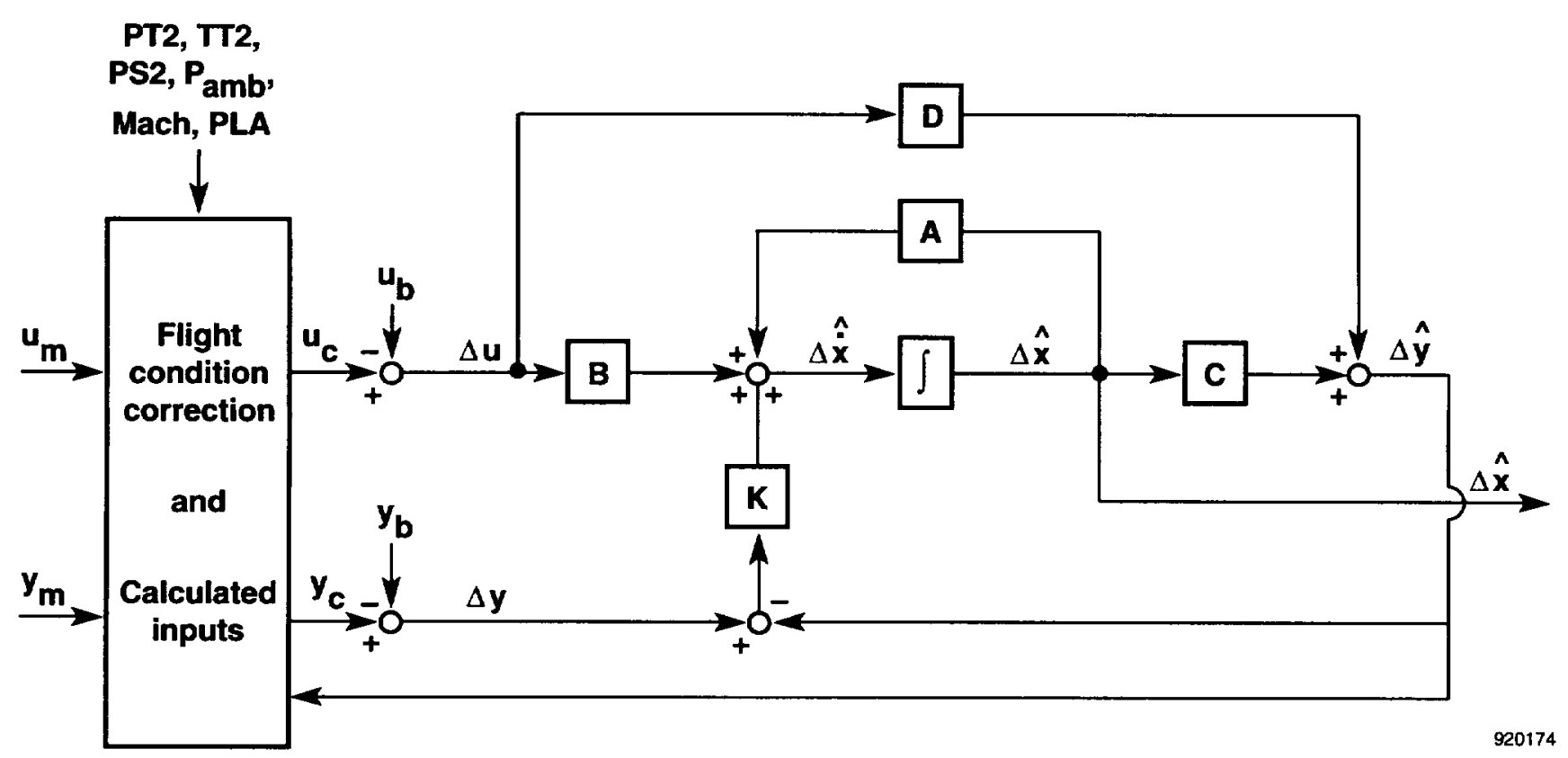

Fig. 4. Extended Kalman filter structure.

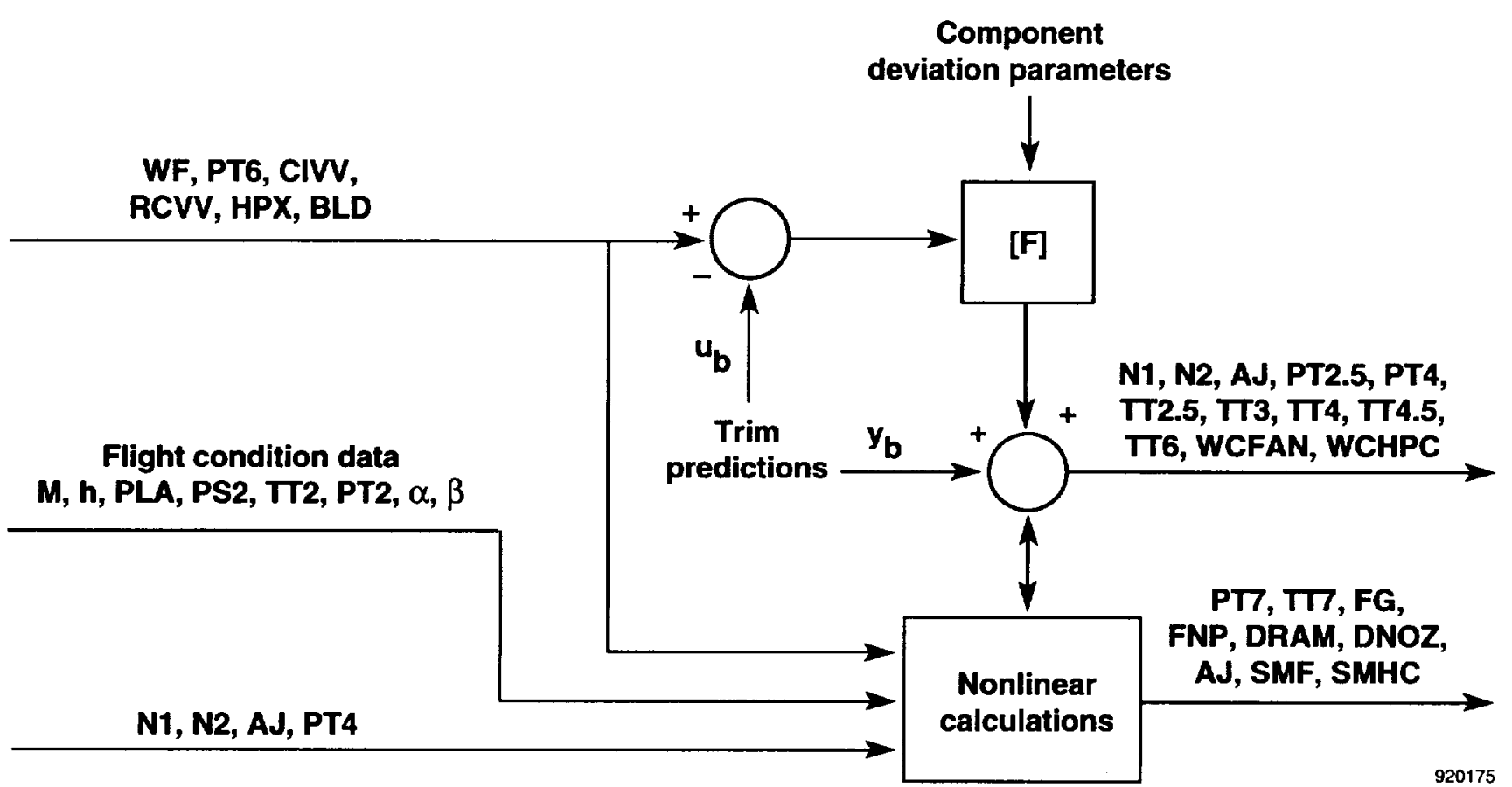

Fig. 5. Compact propulsion system model structure. 


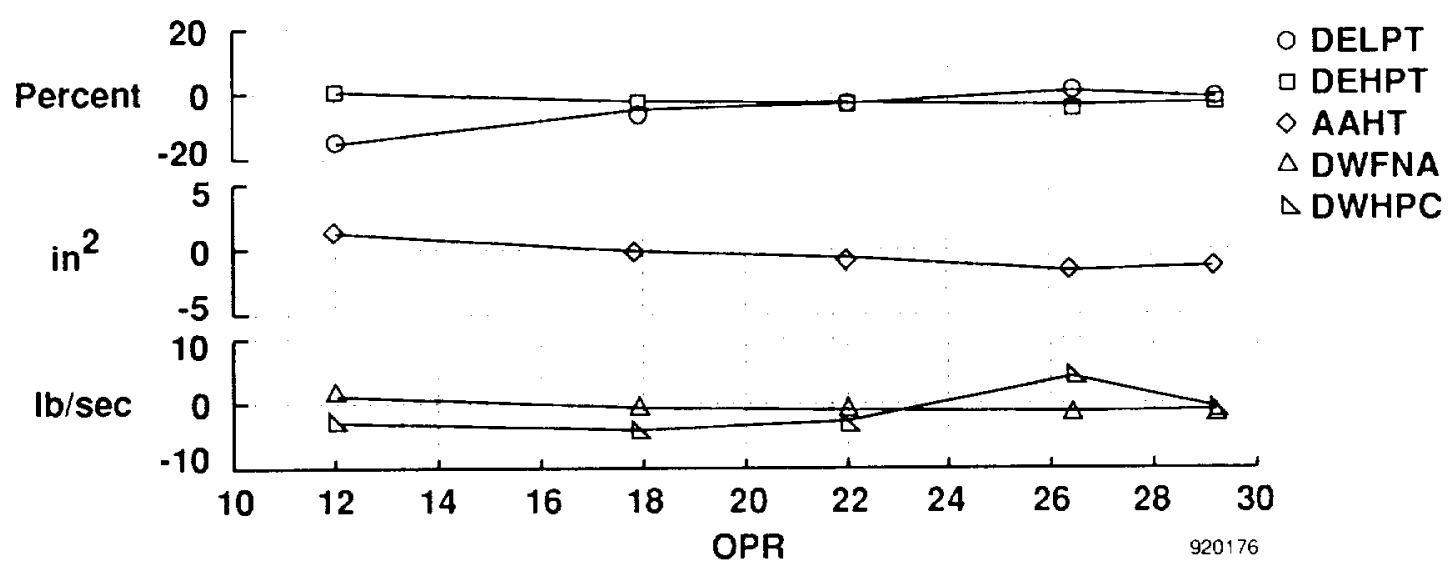

Fig. 6. Kalman filter estimates for the refurbished engine at 0.9 Mach and $30,000 \mathrm{ft}$.

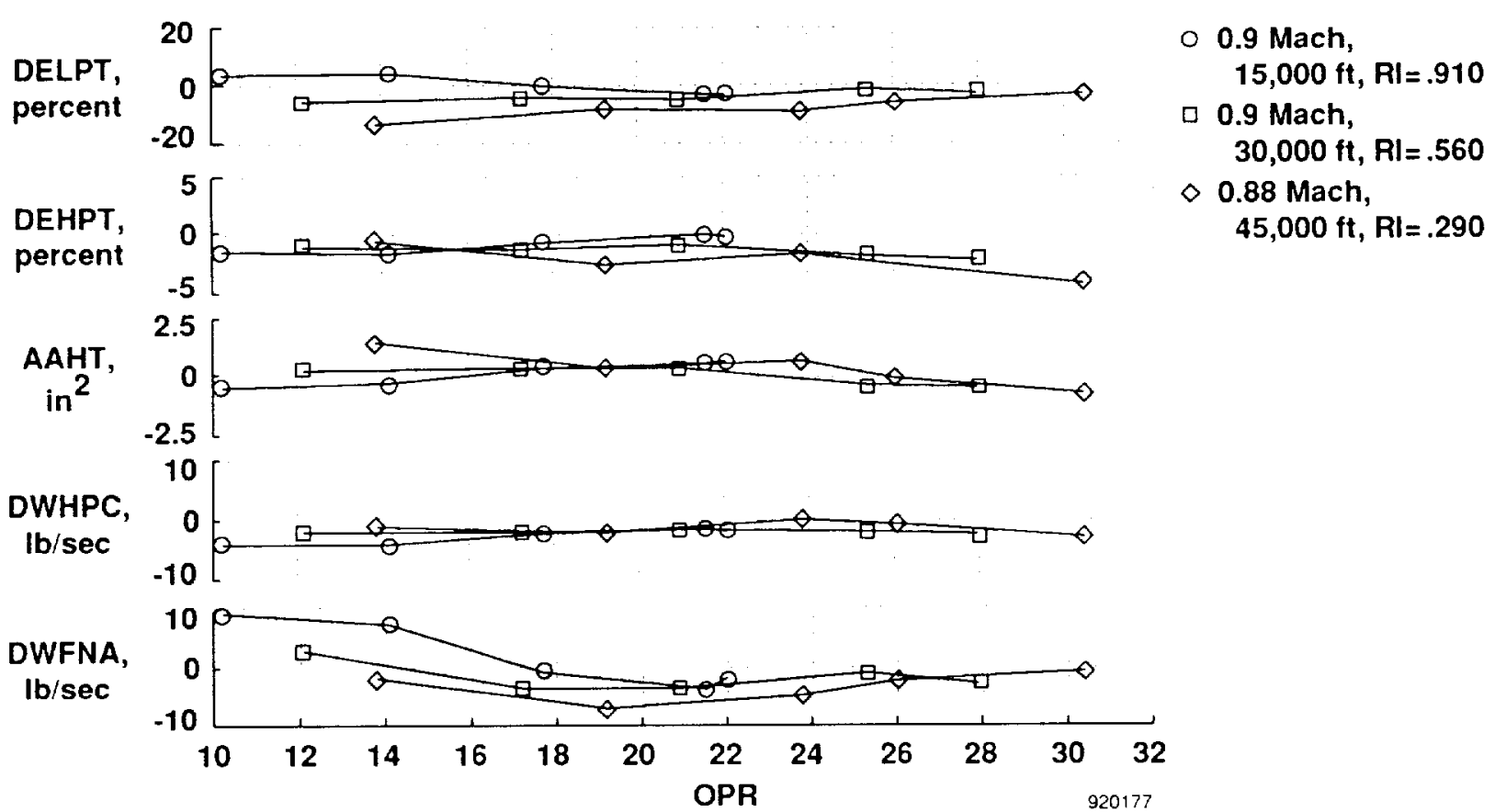

Fig. 7. Kalman filter estimates for the degraded engine at different flight conditions. 


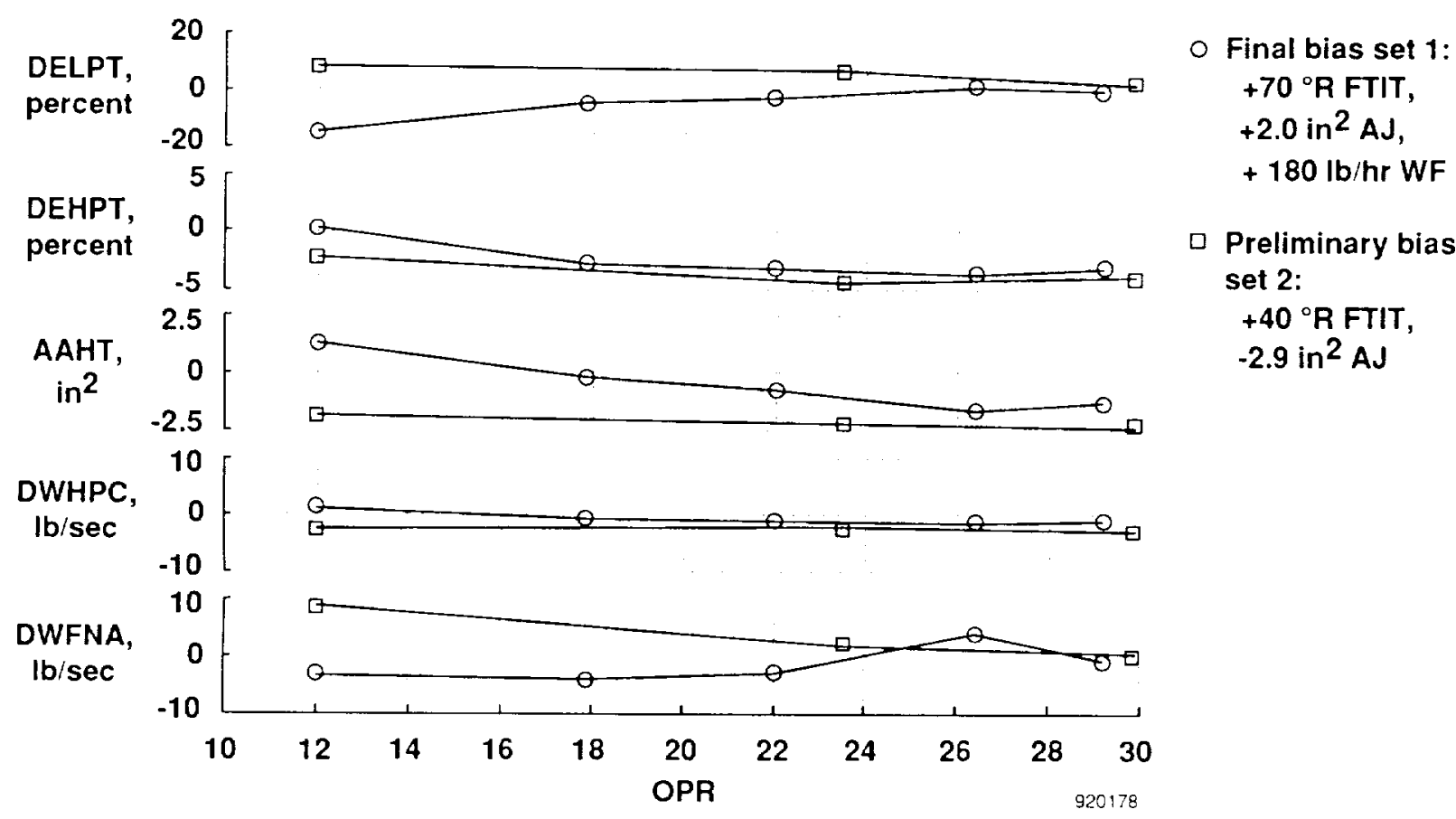

Fig. 8. Kalman filter estimates for the refurbished ongine with different biases al (0.9 Mach and 30,000 ft.

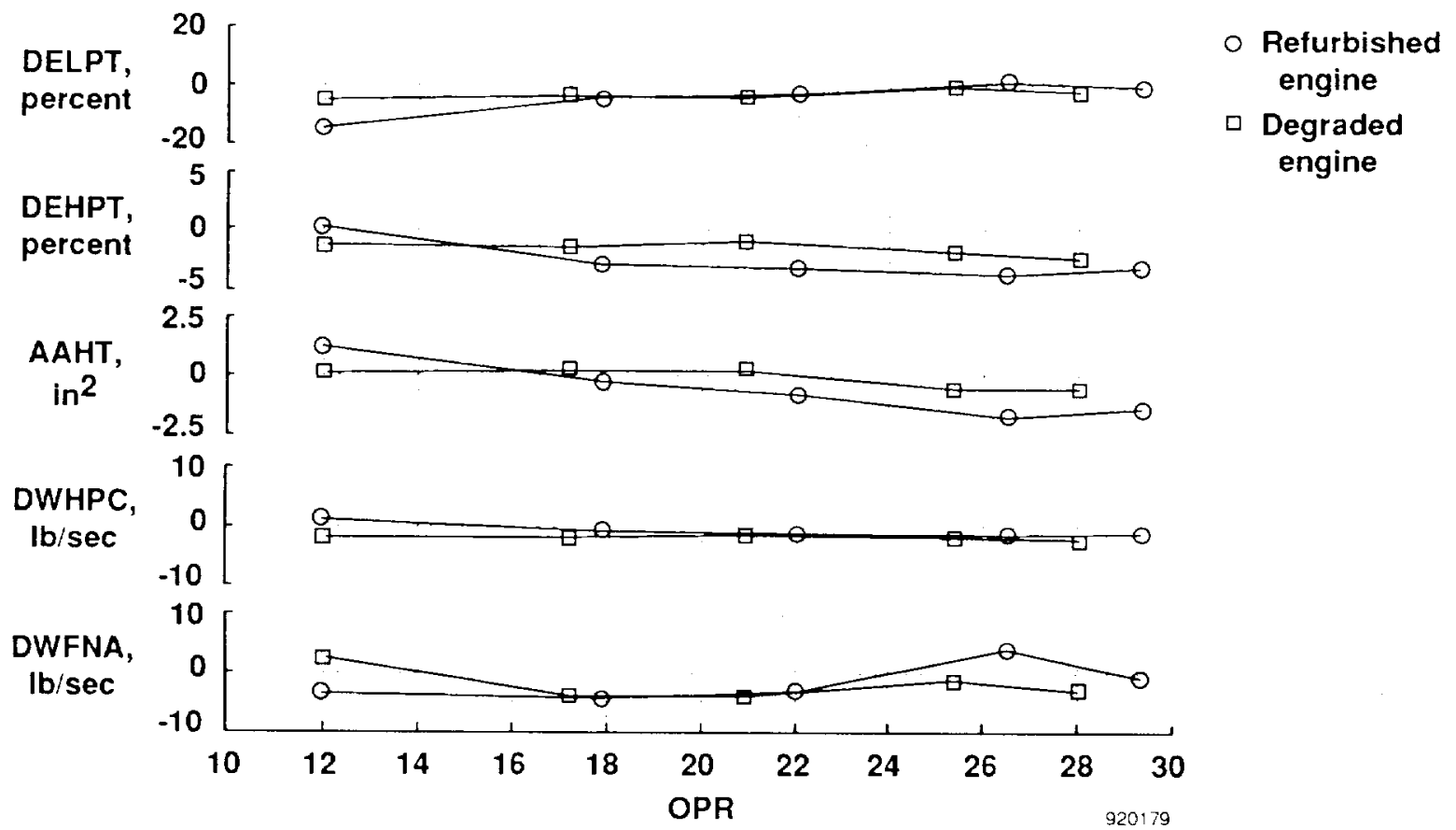

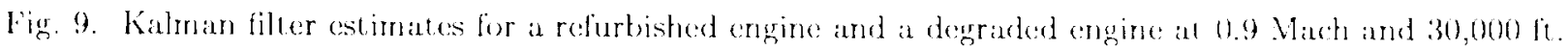




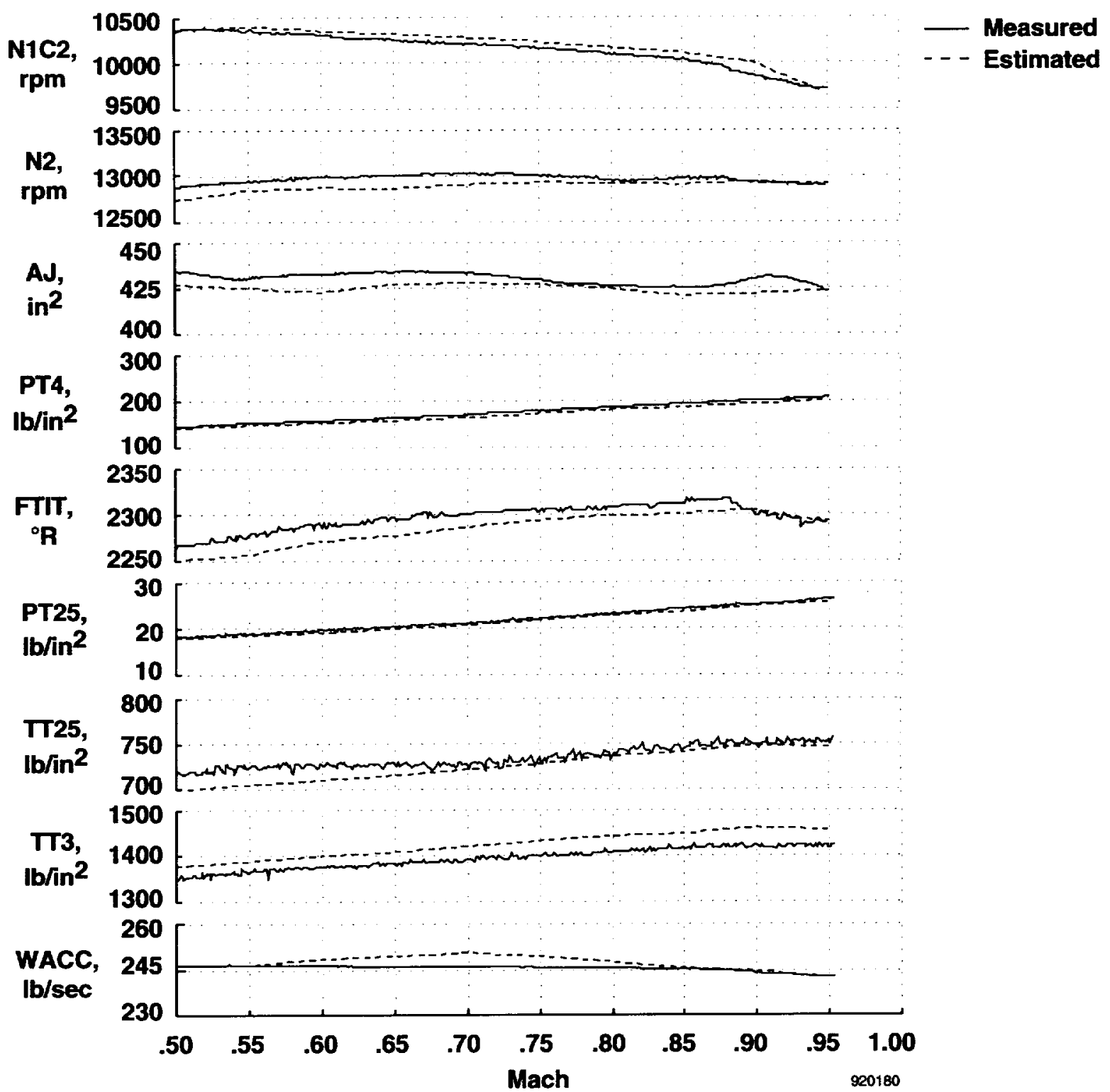

Fig. 10. Compact propulsion system model estimates compared with degraded engine measurements for a militarypower acceleration at $30,000 \mathrm{ft}$. 


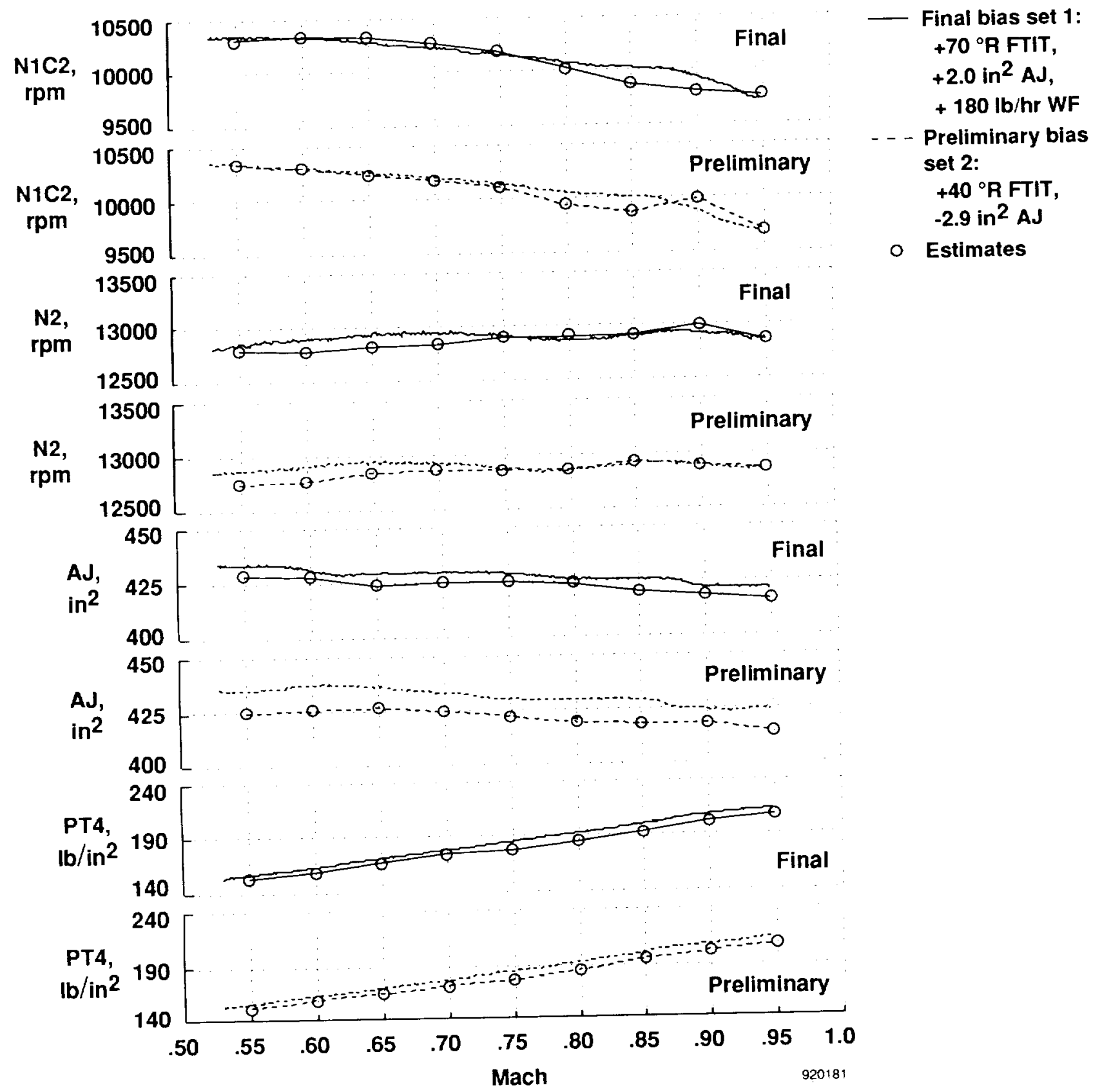

Fig. 11. Compact propulsion system model estimates compared with measurements for the refurbished engine with different biases during a military-power acceleration at $30,000 \mathrm{ft}$. 


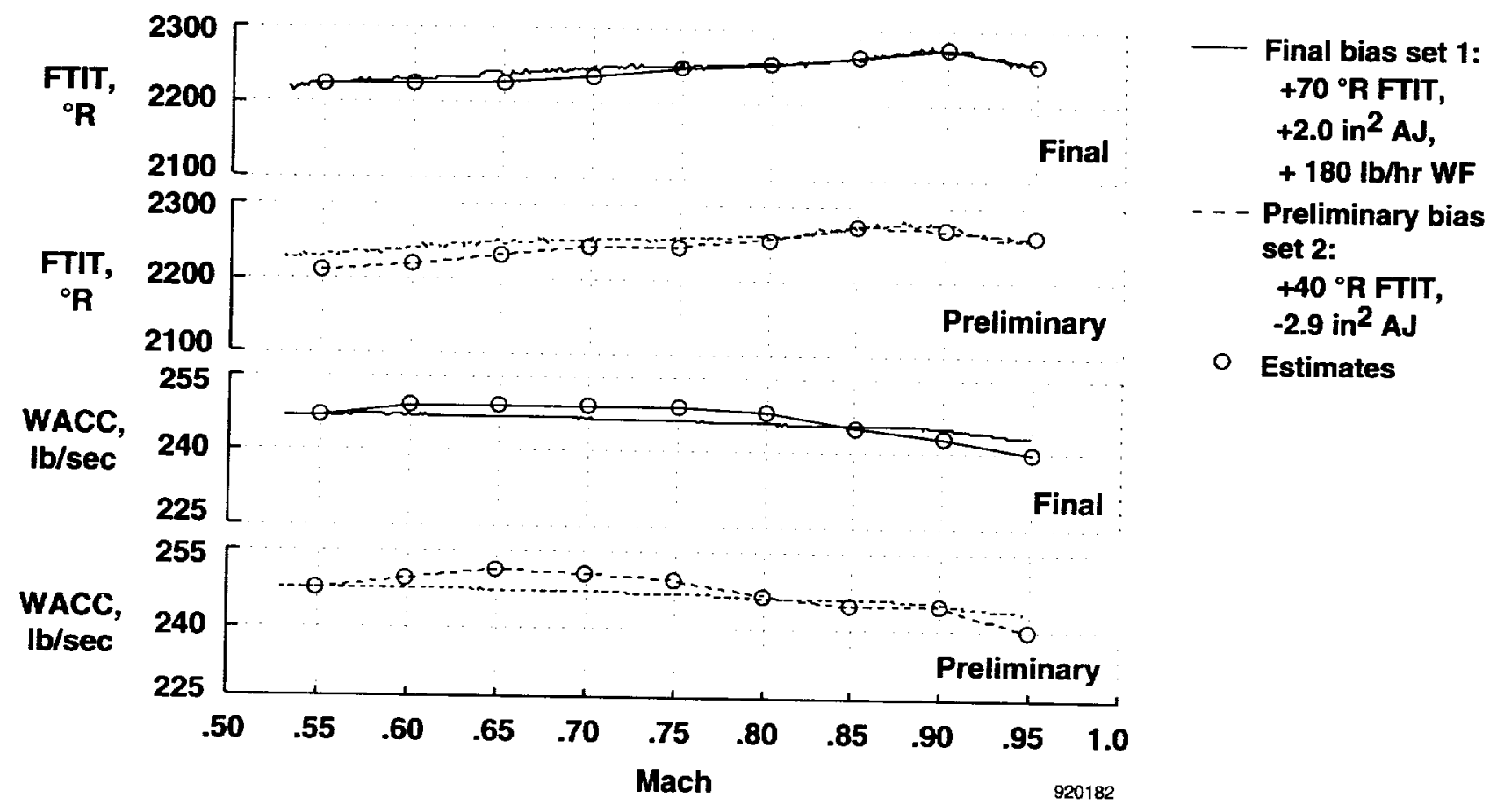

Fig. 11. Concluded. 


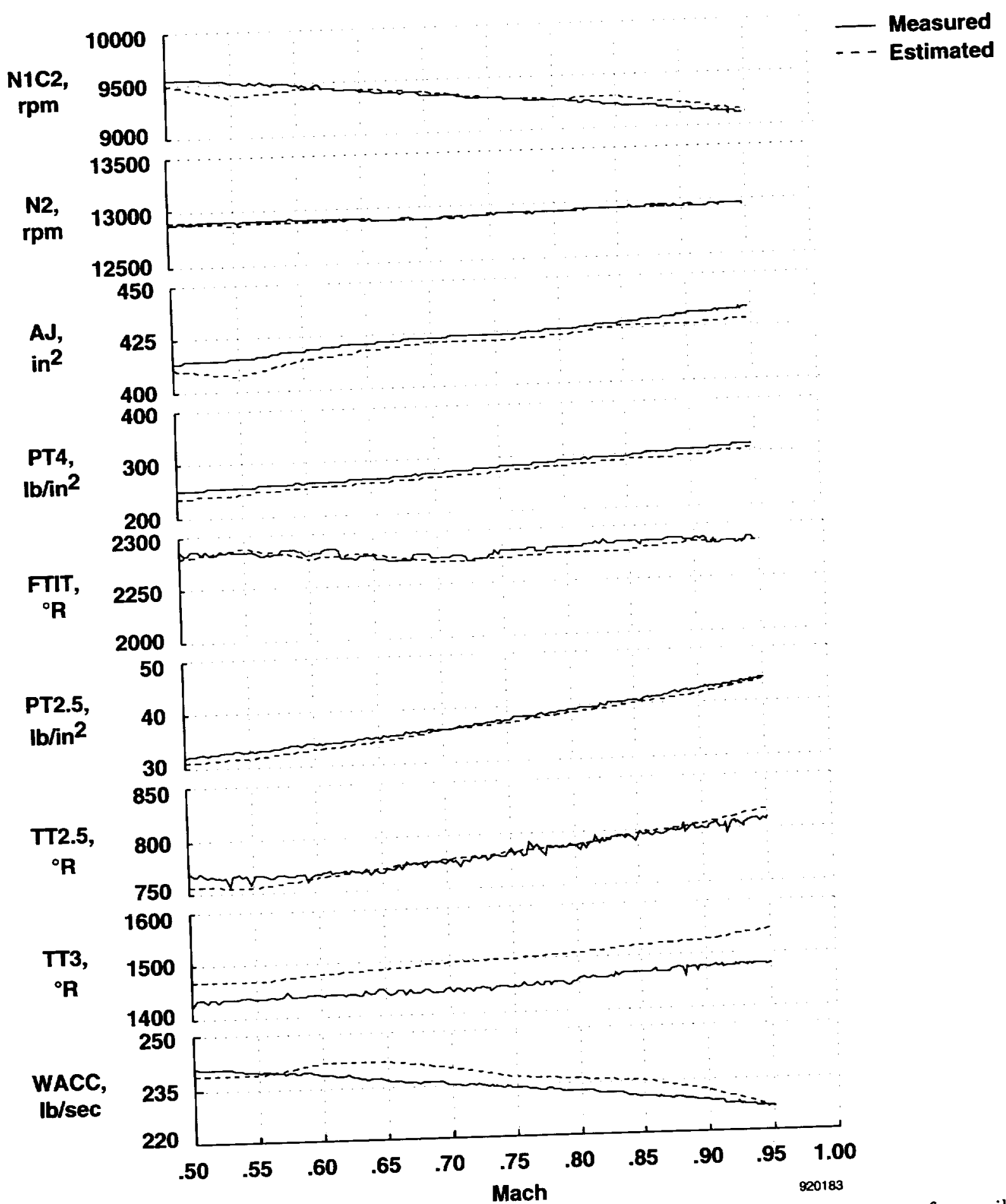

Fig. 12. Compact propulsion system model estimates compared with degraded engine measurements for a militarypower acceleration at $15,000 \mathrm{ft}$. 


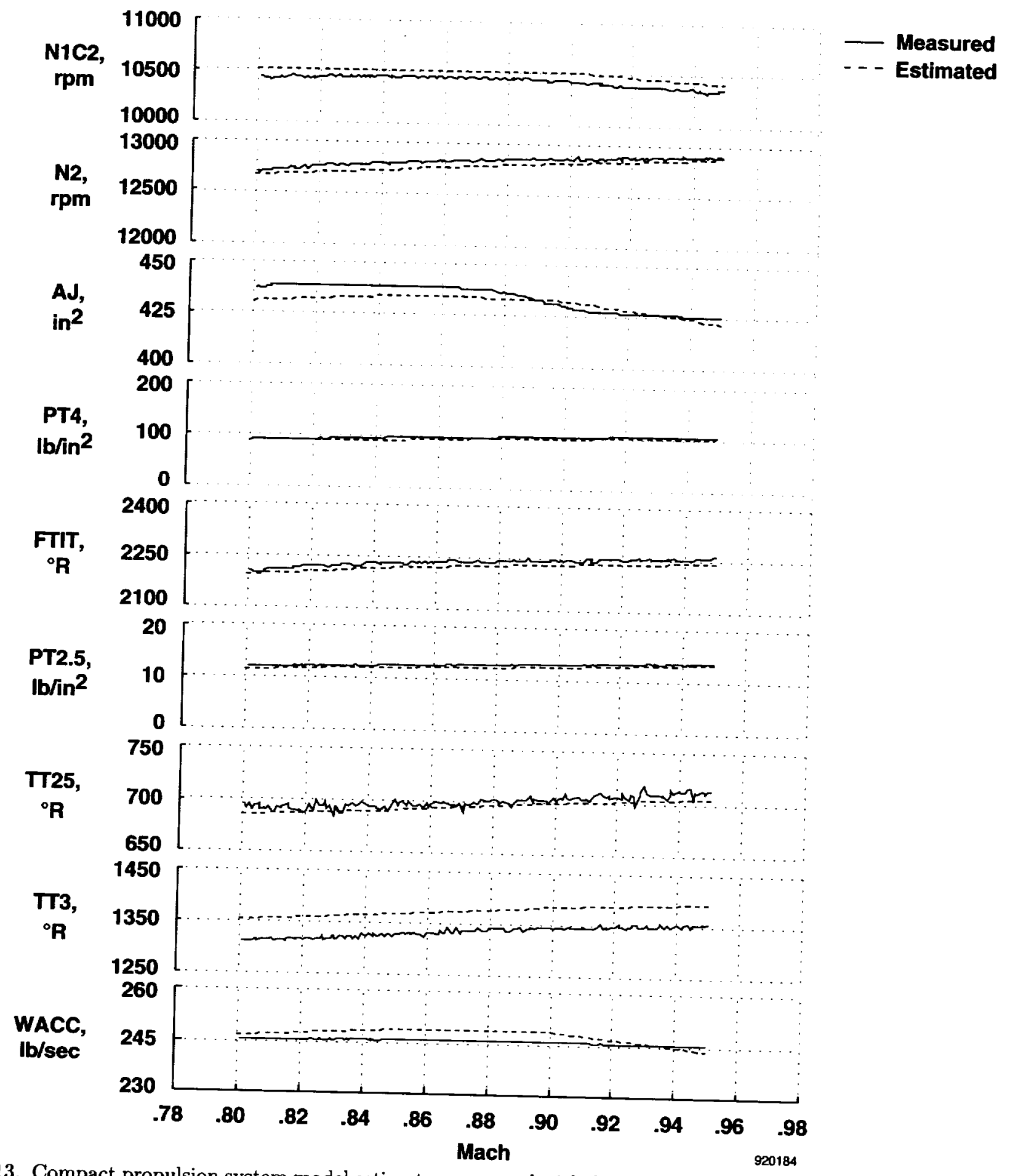

Fig. 13. Compact propulsion system model estimates compared with degraded engine measurements for a military-
power acceleration at $45,000 \mathrm{ft}$. 


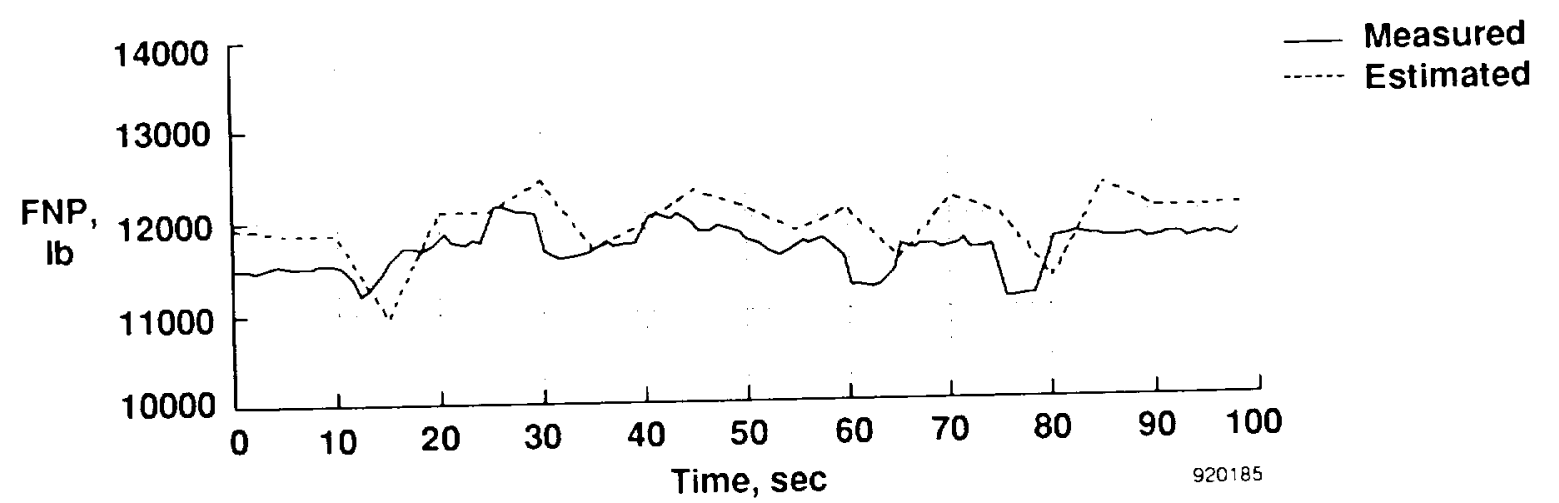

Fig. 14. Compact propulsion system model estimates of net propulsive force (FNP) compared with thrust stand measurements, static conditions at MIL PLA 


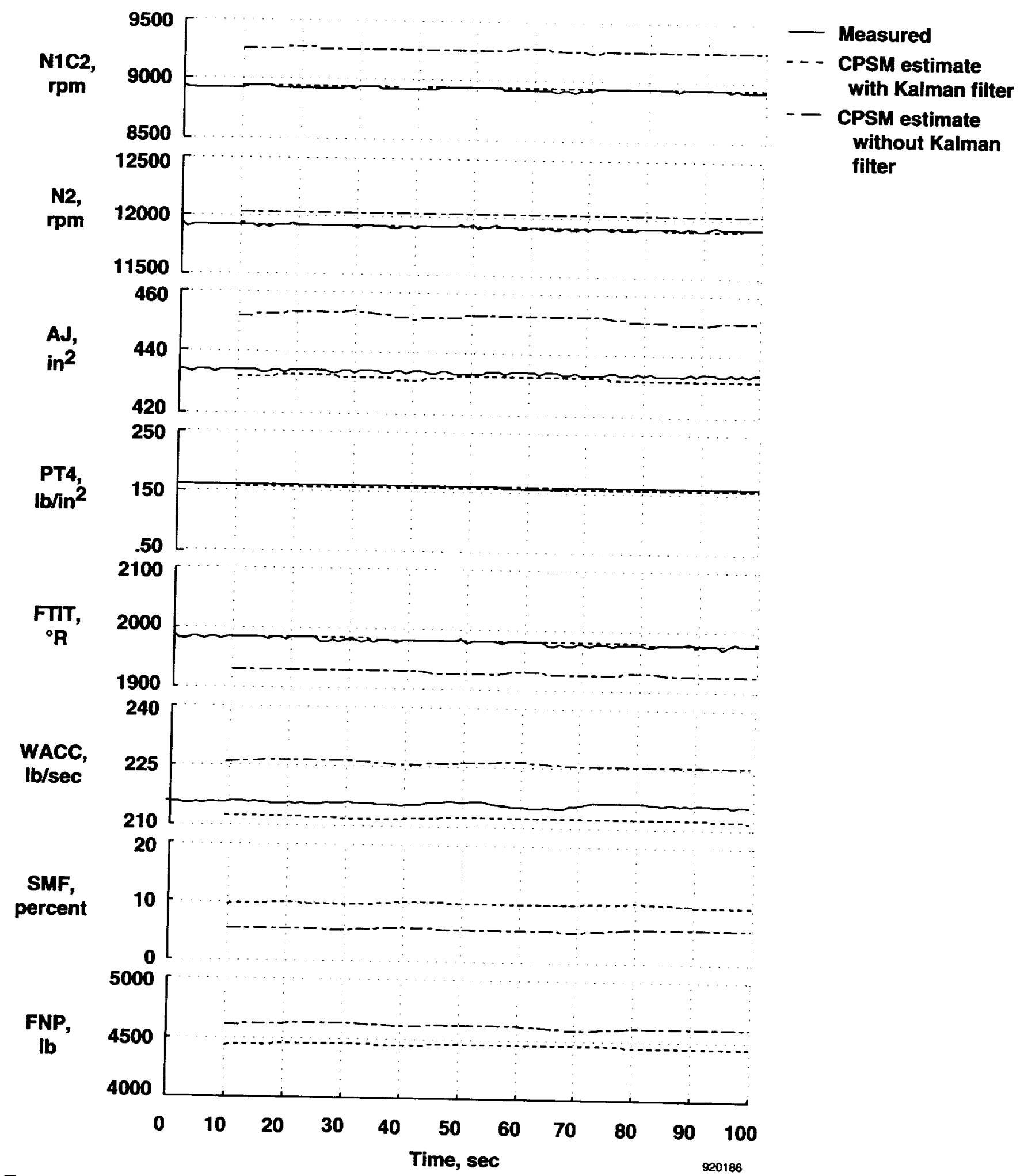

Fig. 15. Compact propulsion system model estimates with and without Kalman filter input compared with refurbished engine measurements at $0.9 \mathrm{Mach}, 30,000 \mathrm{ft}$, and $60^{\circ}$ power lever angle. 



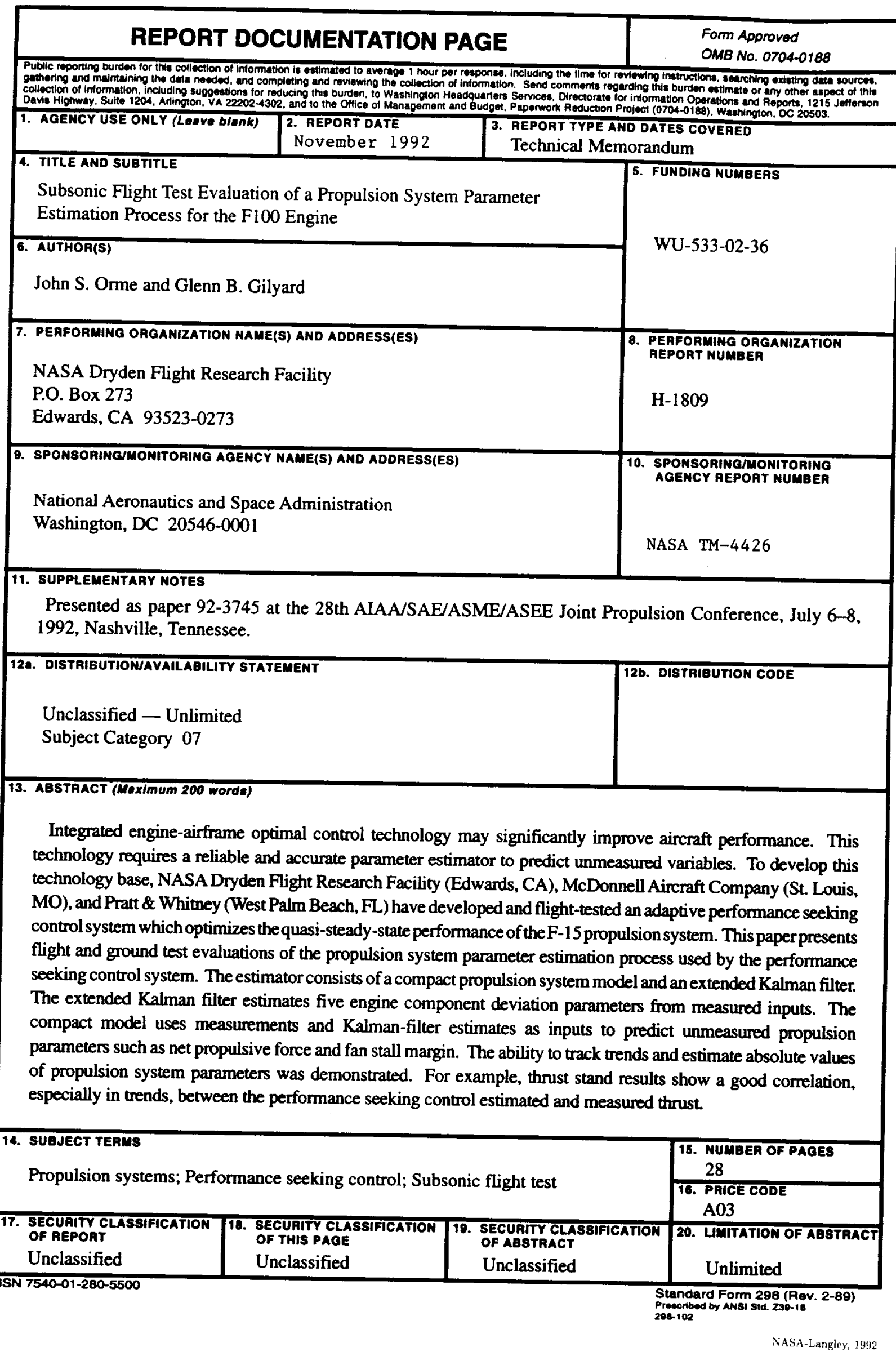

